\title{
New insights into the immunopathology and control of dengue virus infection
}

\author{
Gavin Screaton ${ }^{1}$, Juthathip Mongkolsapaya ${ }^{1,2}$, Sophie Yacoub ${ }^{1,3}$ and \\ Catherine Roberts ${ }^{1}$
}

Abstract | Dengue virus poses a major threat to global public health: two-thirds of the world's population is now at risk from infection by this mosquito-borne virus. Dengue virus causes a range of diseases with a small proportion of infected patients developing severe plasma leakage that leads to dengue shock syndrome, organ impairment and bleeding. Infection with one of the four viral serotypes results in the development of homotypic immunity to that serotype. However, subsequent infection with a different serotype is associated with an increased risk of developing severe disease, which has led to the suggestion that severe disease is triggered by immunopathology. This Review outlines recent advances in the understanding of immunopathology, vaccine development and human monoclonal antibodies produced against dengue virus.

Aedes mosquito vector The genus of mosquito by which dengue virus is transmitted; the primary vector being Aedes aegypti followed by Aedes albopictus.

${ }^{1}$ Division of Immunology and Inflammation, Department of Medicine, Hammersmith campus, Imperial College London, London W12 ONN, UK.

${ }^{2}$ Dengue Hemorrhagic Fever Research Unit, Office for Research and Development, Siriraj Hospital, Mahidol University, Bangkok 10700, Thailand.

${ }^{3}$ Oxford University Clinical Research Unit, Wellcome Trust Major Overseas Programme, Ho Chi Minh City, Vietnam. Correspondence to G.S. e-mail: g.screaton@imperial.ac.uk doi:10.1038/nri3916
Dengue is a positive-sense RNA virus belonging to the Flaviviridae family. There are four distinct serotypes dengue virus serotype 1 (DENV1) to DENV4 - and several genotypes within each serotype. Since the 1950s, there has been considerable expansion in the geographic spread of dengue and an exponential rise in disease incidence. It is estimated that the annual global incidence is 390 million cases, of which 96 million are clinically apparent ${ }^{1}$. There are several factors that drive this pandemic, including globalization, the spread of the Aedes mosquito vector, inadequately planned urbanization and the absence of a licensed vaccine or anti-dengue therapeutics ${ }^{2}$.

The clinical phenotype of dengue can vary depending on several factors, of which age, genetic predisposition and background immunity are major determinants. However, most clinical infections result in a selflimiting febrile illness termed dengue fever. The hallmark feature of severe disease is increased capillary permeability, causing plasma leakage, which can lead to haemodynamic compromise and dengue shock syndrome (DSS) (BOX 1). If untreated, severe disease can lead to a mortality rate of up to $20 \%$ of affected individuals but with expert management and primarily careful fluid replacement, this can be reduced to less than $1 \%^{2}$.

The pathogenesis of severe disease is thought to be due, at least in part, to immune mechanisms in which antibody enhancement and $\mathrm{T}$ cell immunopathology probably have key roles. These theories have served to explain the observation that the development of severe disease is associated with serial infection with dengue viruses of different serotypes. However, because of this risk of severe disease in sequential infections, developing a safe vaccine that provides protection against all four serotypes has been challenging. There have been several advances in understanding and tackling dengue virus infection over the past decade, including viral epitope mapping and defining conserved neutralizing antibodies, as well as the publication of the first Phase III vaccine efficacy trials. This Review focuses on the adaptive immune response to dengue virus infection, the challenges of developing a dengue virus vaccine and new insights from the study of human monoclonal antibodies (mAbs).

\section{Dengue virus}

Dengue virus is a relatively simple positive-sense singlestranded RNA virus that is $50 \mathrm{~nm}$ in diameter and has three structural proteins - capsid (C) protein, precursor membrane (prM) protein and envelope (E) protein - as well as seven non-structural (NS) proteins termed NS1, NS2A, NS2B, NS3, NS4A, NS4B and NS5 (FIG. 1). Studies using X-ray crystallography and cryo-electron microscopy (cryo-EM) have shed considerable light on structural aspects of the flaviviral life cycle ${ }^{3-9}$ (discussed later).

E protein and prM protein form the glycoprotein shell of the virus, and E protein is responsible for host cell binding and entry ${ }^{10}$. Dengue E protein has two $\mathrm{N}$-linked glycosylation sites and is divided into three domains 


\section{Box 1 |Clinical manifestations and treatment of dengue virus infection}

- The majority of patients infected with one of the four dengue virus serotypes are either asymptomatic or present a self-resolving febrile illness, termed dengue fever, that lasts 4-8 days.

- Key clinical manifestations include high fever, headache, retro-orbital pain and muscle pain, as well as other well-recognized signs including rashes, abdominal pain, vomiting and mucosal bleeding.

- The defining feature of severe disease is increased capillary permeability, which causes plasma leakage that can occasionally lead to shock and death ${ }^{146}$.

- Other severe manifestations include haemorrhage and organ impairment, such as hepatitis, myocarditis and encephalitis.

- Clinical symptoms vary by age of the infected individual, with children being more at risk of shock and adults more likely to develop organ impairment and bleeding ${ }^{147}$.

- The treatment of dengue is supportive care, in the form of intravenous fluids for patients with haemodynamic compromise from plasma leak and for those unable to tolerate oral rehydration.

- There have been several recent clinical trials investigating novel antiviral and immune modulators; however, none of these treatments has demonstrated any clinical benefit in dengue to date ${ }^{148}$.
Cytokine storm

An excessive production of

pro-inflammatory cytokines that occurs during acute

dengue infection and that has been proposed to drive the vascular leak. termed EDI, EDII and EDIII ${ }^{5}$. During viral assembly in the endoplasmic reticulum, 180 copies of E protein associate with 180 copies of prM protein to form 60 trimeric (heterohexameric) spikes, which gives immature virions their characteristic spiky appearance ${ }^{10}$ (FIG. 2a). In the trans-Golgi network, prM protein is cleaved at a membrane proximal site by host-encoded furin protease, resulting in a membrane-anchored $\mathrm{M}$ stump and a pr molecule that remains associated with the virion until it is secreted. Upon secretion from the host cell, pr protein disassociates to leave the 'mature virion', which has a smooth structure (FIG. 2b).

The cleavage of prM protein is not complete in all dengue virions, leaving a proportion of partially mature dengue virions that contain a varying amount of cleaved and uncleaved prM protein ${ }^{11-14}$. The cleavage of prM protein is more efficient in certain cell types, particularly primary human cells such as dendritic cells, compared with the cleavage event in insect cells or tumour cell lines such as Vero ${ }^{15,16}$. Fully immature dengue viruses contain regular trimeric E-prM protein spikes and are non-infectious ${ }^{17,18}$. By contrast, the partially mature forms, some of which are infectious, have a less regular structure, with areas that are spiky and contain prM protein-E protein trimers and areas that are smooth and are proposed to contain E protein dimers ${ }^{19}$.

Finally, virions attach to cells, possibly through $\mathrm{EDIII}^{10}$. Several host proteins - such as heparan sulfate, dendritic cell-specific ICAM3-grabbing non-integrin (DC-SIGN; also known as CD209), heat shock protein $70 \mathrm{kDa}$ (HSP70), HSP90, mannose receptor, CD14, $\mathrm{T}$ cell immunoglobulin and mucin domains (TIMs; also known as HAVCRs), TAM receptor protein tyrosine kinases and laminin — have been suggested to have a role in dengue virus binding, but there is no single receptor yet defined that is necessary for entry ${ }^{20}$. Following endocytosis, acidification in the early endosome triggers a dramatic reorganization of the viral envelope, from the dimer form to a new trimeric conformation.
This exposes the fusion loop at the tips of the trimeric spikes, which then fuses with the endocytic membrane and allows the viral nucleic acid to be released into the host cell cytoplasm ${ }^{10}$ (FIG. 1).

\section{Immune involvement of dengue pathogenesis}

There are several key observations that suggest a role for the immune system in dengue pathogenesis: first, severe dengue usually, but not exclusively, occurs with secondary infection, implying that priming of the adaptive immune system to one dengue virus serotype leads to disease enhancement during a secondary infection with a different serotype $e^{2,21,22}$. Second, the peak in symptoms occurs when viral loads are rapidly decreasing, implying that immunopathology may be driven as a consequence of viral control ${ }^{23,24}$. Third, higher viral loads and/or soluble NS1 levels in patients with dengue haemorrhagic fever versus patients with dengue fever predispose to increased disease severity, which manifests when the virus is controlled and viral loads fall ${ }^{23-25}$. Finally, the peak in symptoms, vascular leak and viral control coincide with a cytokine storm, which is characterized by high circulating levels of many proinflammatory mediators such as tumour necrosis factor (TNF), soluble TNF receptor 1 (sTNFR1), sTNFR2, interferon- $\gamma(\mathrm{IFN} \gamma)$, CXC-chemokine ligand 8 (CXCL8), CXCL9, CXCL10, CXCL11, CC-chemokine ligand 5 (CCL5) and vascular endothelial growth factor A (VEGFA), as well as the anti-inflammatory

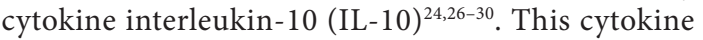
storm has been proposed to trigger increased vascular permeability and resolves relatively quickly upon patient convalescence.

The exact mechanisms underlying the capillary leak are probably more complex than a cytokine storm, which is also associated with other diseases with very different clinical phenotypes, such as graft-versus-host disease $^{31}$, septic shock ${ }^{32}$ and influenza virus infection ${ }^{33}$. Dengue virus may cause increased vascular permeability through binding to the endothelial glycocalyx layer, which lines the luminal surface of microvessels, providing vital barrier functions to capillaries. Both the virus and NS1 protein have been shown to bind to heparan sulfate, a major component of the glycocalyx layer ${ }^{34,35}$, which may in turn alter the permeability of capillaries (FIG. 3).

NS1-mediated complement activation may also play a part in the altered capillary permeability through the generation of the anaphylatoxins $\mathrm{C} 3 \mathrm{a}$ and $\mathrm{C} 5 \mathrm{a}$ and the terminal complement complex C5b-C9 (REF. 23). High C5b-C9 levels in plasma and pleural fluid have been demonstrated in patients with dengue shock, and patients who were high producers of C5b-C9 had more signs of plasma leakage ${ }^{23}$. Furthermore, NS1 may have an immunomodulating role by binding to and reducing the functional capacity of $\mathrm{C} 4$, thereby altering the classical and lectin complement pathways ${ }^{36}$.

Innate immune cells also have a role in dengue pathogenesis; for example, several studies suggest that mast cells have a role in both protection against and pathogenesis of dengue. Upon interaction with dengue virus, 
mast cells release chemokines that recruit T cells, natural killer (NK) cells and NKT cells to control the infection ${ }^{37}$. By contrast, the interaction also leads to the secretion of mediators such as chymases - proteases that may contribute to vascular leakage. The level of chymases is correlated with disease severity ${ }^{37}$.
Overall, the well-established association of severe dengue with secondary infection, the evidence of extreme immune activation in severe infection and the coincidence of viral control with the peak of symptoms has led to the detailed study of both T cell- and B cell-mediated adaptive immune responses, which are reviewed here.

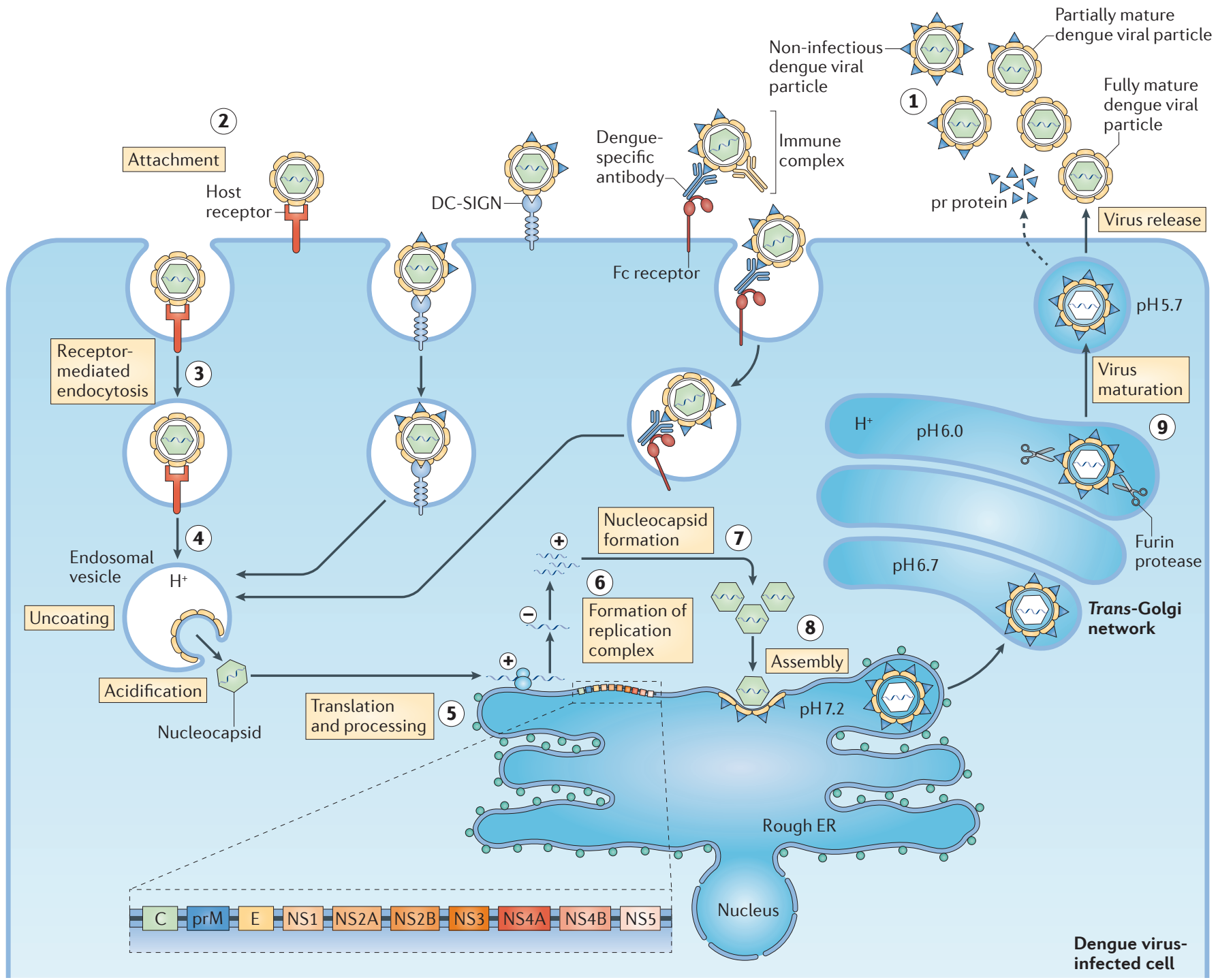

Figure 1 | The life cycle of dengue virus. Dengue virus exists as a number of different viral forms depending on the degree of precursor membrane (prM) protein cleavage. Fully immature dengue virus particles contain a full complement of prM proteins and are non-infectious, whereas all prM proteins are cleaved in fully mature virus particles. A number of intermediate, partially mature forms exist in which some prM proteins have been cleaved and some remain intact. Fully mature and some of the partially mature virus particles are infectious (step 1). The dengue viral replication process begins when a virion attaches directly to a diverse group of host cell receptors or when the Fc portion of a dengue virus-containing immune complex attaches to a Fc receptor on the target cells (step 2) and subsequently enters the cell by receptor-mediated endocytosis (step 3). Acidification of the endosomal vesicles triggers conformational changes in the virion, resulting in an irreversible trimerization of the viral envelope (E) protein (not shown). This exposes the fusion peptide and mediates fusion between the viral and the endosomal membranes, allowing the release of the nucleocapsid into the cytoplasm. The viral RNA is released into the cytoplasm and presented to the rough endoplasmic reticulum (ER) (step 4). At the ER, viral RNA is translated into a single polyprotein that is processed by viral and host proteases (step 5). After the viral replication complex is synthesized, viral RNA translation switches off, and RNA synthesis begins by the transcription of an antisense viral RNA followed by the amplification of viral RNA (step 6). The newly synthesized RNA is subsequently packaged by capsid (C) protein, forming a nucleocapsid (step 7). Virus assembly occurs on the surface of the ER when the nucleocapsid buds into the ER lumen, resulting in non-infectious, immature viral particles (step 8). Immature viral particles are transported through the Golgi into the trans-Golgi network, where acidification induces conformational changes of the virion and exposes the furin cleavage sites. The host protease furin cleaves between pr protein and $\mathrm{M}$ protein, with the pr protein remaining associated until the virion is released in the neutral $\mathrm{pH}$ of the extracellular millieu (step 9). DC-SIGN, dendritic cell-specific ICAM3-grabbing non-integrin; NS proteins, non-structural proteins. 
a

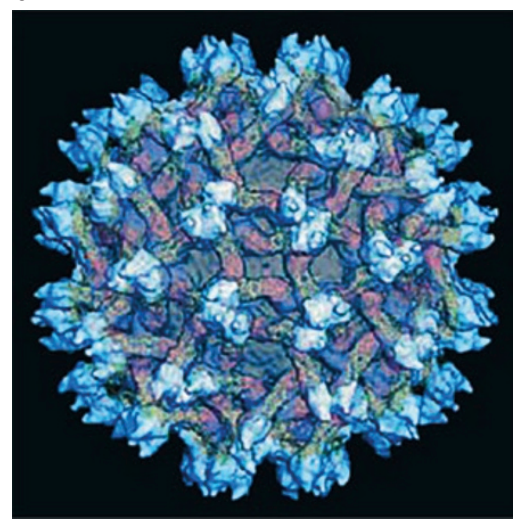

Immature particle at neutral $\mathrm{pH}$ b

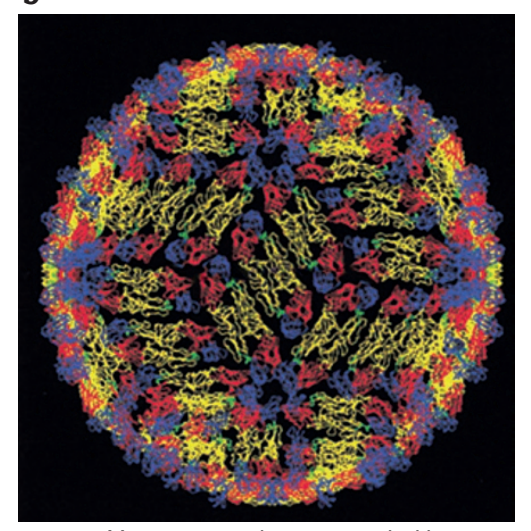

Mature particle at neutral $\mathrm{pH}$

Figure 2 | Structure of the dengue viral particle. a | The structure of an immature dengue viral particle shows the arrangement of envelope (E) proteins in pink and precursor membrane (prM) proteins in light blue. $\mathbf{b}$ |The mature dengue virus shows the arrangement of the E proteins into a smooth particle. Figure in part a from REF. 149, Nature Publishing Group. Figure in part b reprinted with permission from REF. 3, Elsevier.

Tetramer staining A technique used to track antigen-specific T cells by flow cytometry. Biotinylated monomeric MHC molecules are folded in vitro together with a specific peptide in the binding groove. These peptide-MHC complexes are tetramerized using a fluorescently labelled streptavidin molecule. The tetramers bind $T$ cells that express T cell receptors specific for the cognate peptide-MHC complex.

Original antigenic sin An immune response to serial exposure to two pathogens of similar yet distinct sequences. Upon a second infection, rather than making an entirely new immune response to antigens of the secondary infecting pathogen,

cross-reactive and potentially suboptimal memory cells that were generated during the first infection are expanded. Original antigenic sin was first described for antibody responses but has also been demonstrated in T cell responses.
The role of $T$ cells in dengue pathogenesis. The association of severe dengue symptoms with a rapid decline in viral loads and a peak of pro-inflammatory cytokine secretion have led to the proposal of a role for a $\mathrm{T}$ cellmediated immune response in driving immunopathology in severe dengue. There has been much study of $\mathrm{T}$ cell responses in dengue, but the contribution of these responses to pathogenesis and protection remains controversial $^{38}$. Reports have demonstrated potent $\mathrm{T}$ cell responses in dengue-infected individuals, and many dengue $\mathrm{T}$ cell epitopes have been mapped in humans and mouse models ${ }^{39-46}$. Responses to NS3 seem to be immunodominant in humans, although $\mathrm{CD} 8^{+}$and $\mathrm{CD} 4^{+}$ $\mathrm{T}$ cells that respond to epitopes across the whole virus proteome have been observed ${ }^{39,41,44,46-50}$.

The magnitude of the $\mathrm{T}$ cell response positively correlates with disease severity ${ }^{39,42,43,51,52}$ with many cells during the acute disease displaying markers of both proliferation and programmed cell death ${ }^{42}$. Some scientists have questioned the relevance of T cells to dengue pathogenesis and control because of the relatively low numbers of circulating $\mathrm{T}$ cells seen during acute infection that increase rapidly following viral clearance ${ }^{42,53,54}$. However, a recent study showed that skin blister fluid taken from dengue-infected patients contained more dengue-specific T cells than peripheral blood, suggesting that dengue-specific $\mathrm{T}$ cells may migrate from the peripheral blood to the skin during acute infection and return upon viral clearance ${ }^{55}$.

During secondary dengue virus infection, responding $\mathrm{T}$ cell populations rapidly expand and can account for up to $20 \%$ of circulating $\mathrm{T}$ cells $\mathrm{s}^{53}$, and cross-reactive $\mathrm{T}$ cells in dengue have been well studied ${ }^{39,42,43,46,50,54,56,57}$. Using double tetramer staining with tetramers containing peptides from either the primary or secondary infecting viruses, we and others have studied the cross-reactivity of $\mathrm{CD}^{+} \mathrm{T}$ cell responses ${ }^{42,43,54}$. These studies provide evidence for original antigenic sin in secondary $\mathrm{T}$ cell responses to dengue virus. During a secondary infection, there is a large increase in the number of $\mathrm{T}$ cells that bind to tetramers loaded with peptides derived from the primary dengue virus infection $^{42}$. Some of these cells cross-react with tetramers loaded with peptide derived from the secondary infecting virus, whereas others show lower avidity for the tetramer from the secondary virus and no functional responses to the secondary virus-derived peptides. Original antigenic sin has previously been reported for $\mathrm{CD}^{+} \mathrm{T}$ cell responses to influenza virus ${ }^{58}$ and lymphocytic choriomeningitis virus (LCMV) ${ }^{59}$, and also appears to operate in dengue virus infection ${ }^{42}$. Some dengue-specific $\mathrm{T}$ cell populations that expand during secondary infection have been shown to be fully crossreactive to antigens of the serotypes of the primary and secondary infections, whereas other populations show preference for the primary-infecting serotype $\mathrm{e}^{42,43,50}$. The expansion of these low-avidity cells specific for the primary infection may delay viral clearance and thereby lead to higher viral loads.

In another study, the presence of original antigenic sin was demonstrated in the dengue $\mathrm{T}$ cell response, but the magnitude of the response did not seem to be compromised $^{44}$. This study differed from the one described earlier in that it measured functional responses to peptide stimulation and did not measure non-functional cells with tetramer staining or formally show crossreactivity, which was inferred on the basis of the similarity of peptide sequences. Thus, in the absence of a good animal model of disease, it remains controversial whether the expansion of low-avidity cross-reactive $\mathrm{T}$ cells in secondary dengue infection contributes to disease pathogenesis.

Study of the function of dengue-specific T cells has revealed an interesting difference between mild and severe infections. During milder dengue fever illness, $\mathrm{CD}^{+} \mathrm{T}$ cells degranulate but produce lower levels of pro-inflammatory cytokines ${ }^{39}$. By contrast, during severe primary and secondary infections, a high proportion of $\mathrm{CD}^{+} \mathrm{T}$ cells produce the cytokines TNF and IFN $\gamma$ but do not undergo marked degranulation, potentially negatively affecting virus control while enhancing disease pathogenesis and immunopathology ${ }^{39} . \mathrm{CD}^{+} \mathrm{T}$ cell populations also expand during dengue virus infection and, similarly to $\mathrm{CD} 8^{+} \mathrm{T}$ cells, the magnitude of the $\mathrm{CD} 4^{+} \mathrm{T}$ cell response correlates with disease severity ${ }^{39,46}$. Interestingly, several studies have reported the generation of dengue-specific $\mathrm{CD} 4^{+} \mathrm{T}$ cells that express degranulation markers or can lyse peptide-pulsed target cells, which could have a role in the disease ${ }^{39,46,57,60}$.

As mentioned above, the role of $\mathrm{T}$ cells in dengue disease pathogenesis and protection is debated. On the one hand, potent $\mathrm{T}$ cell responses skewed to cytokine production and not degranulation are associated with, and potentially drive, severe disease $\mathrm{e}^{42,43}$. On the other hand, in milder disease, $\mathrm{CD} 4^{+}$or $\mathrm{CD} 8^{+} \mathrm{T}$ cells may have a beneficial role in controlling virus replication. An analysis of $\mathrm{T}$ cell responses in individuals from a large Sri Lankan dengue cohort has suggested a role for T cells in protecting from dengue: higher-amplitude 
$\mathrm{T}$ cell responses were observed for epitopes presented by protective HLA alleles ${ }^{44}$. However, most HLA association studies in dengue have been small and not repeated ${ }^{61}$. Furthermore, depletion and adoptive transfer of $\mathrm{CD}^{+}$and $\mathrm{CD} 4^{+} \mathrm{T}$ cells in mouse models have suggested a role for these cells in reducing viral loads and protecting from severe disease ${ }^{45,62,63}$. Other investigators who question the importance of $\mathrm{T}$ cells in dengue pathogenesis point out that severe dengue can occur during a primary dengue infection in which cross-reactive $\mathrm{T}$ cells and original antigenic sin would not be operative ${ }^{64}$.

Finally, it has been speculated that the suboptimal efficacy of the recent Sanofi Pasteur vaccine in clinical trial (see later) may in part be driven by the lack of a protective $\mathrm{T}$ cell response, as all of the NS proteins in this tetravalent vaccine derive from the yellow fever virus. We suggest that the generation of an early $\mathrm{T}$ cell response to dengue virus may be protective, whereas the late generation of $\mathrm{T}$ cell populations that have a proportion of low-avidity $\mathrm{T}$ cells and are skewed to inflammatory cytokine production in the absence of degranulation may predispose to immunopathology in the presence of high viral or antigen loads and contribute to the cytokine storm and vascular leak ${ }^{39}$ (FIG. 3).

Antibody-dependent enhancement. The theory of antibody-dependent enhancement (ADE) attempts to explain why severe dengue is usually associated with secondary infections in children and adults ${ }^{21,22,65}$. The $\mathrm{ADE}$ hypothesis posits that pre-existing heterologous antibodies generated in response to a primary infection may not be of sufficient avidity or concentration to neutralize a secondary infection by a different dengue serotype, in which the sequence of E protein may vary by $30-35 \%$ at the amino acid level. Instead, the virus may be opsonized and targeted for uptake into Fc receptor (FcR)-bearing cells, such as monocytes and macrophages, which are major sites of dengue virus replication in vivo (FIG. 3b). It has also been shown that dengue viruses interact with leukocyte immunoglobulin-like receptor B1, which leads to inhibition of FcR-mediated signalling induced by dengue virus-specific antibody complexes and the downstream induction of antiviral type I IFN-stimulated genes ${ }^{66}$.

$\mathrm{ADE}$ can be readily demonstrated in vitro using FcR-expressing cells and has been shown to drive higher viral loads in both mouse and primate models of dengue virus infection ${ }^{67}$. ADE has also been suggested to lead to increased disease severity in infants experiencing primary dengue virus infection during the first year of life when the levels of passively transferred maternal dengue-specific antibodies fall below neutralizing levels ${ }^{21,68-70}$. In mouse models, ADE can increase disease severity, leading to vascular leakage and lethality ${ }^{67,71}$. Polymorphisms in the gene encoding the low-affinity FcR for IgG (FCGR2A) have been suggested to have a role in ADE; there is an association of the $\mathrm{H} / \mathrm{H}$ and $\mathrm{H} / \mathrm{R}$ alleles at position 131 with severe infection, whereas the $131 \mathrm{R} / \mathrm{R}$ allele is associated with protection from severe disease $\mathrm{e}^{72-74}$.
Antibodies directed against prM protein can facilitate FcR-mediated uptake of immature viral particles which, although non-infectious in the absence of antibody, can undergo furin-mediated prM protein cleavage following endocytosis in the host cell, rendering them infectious ${ }^{15,18,75}$. A similar phenomenon has also been demonstrated following ADE driven by antibodies specific for $\mathrm{E}_{\text {protein }}{ }^{76}$. At sub-neutralizing concentrations, almost all antibodies specific for $\mathrm{E}$ and prM proteins can enhance viral uptake, with maximum levels of enhancement occurring at roughly half the concentration required for neutralization 77,78 . In infections with West Nile virus, a structurally related flavivirus, it has been estimated that around 15-29 E protein-specific antibodies bound to a virion will promote $\mathrm{ADE}^{78}$. The exact role of $\mathrm{ADE}$ in human infection is much debated and has been a great concern in vaccine studies. The very recent data (described later) from the Sanofi Pasteur vaccine trials may be the first evidence to substantiate this concern.

In summary, antibodies and $\mathrm{T}$ cells have been implicated in the generation of both protective and pathogenic responses during dengue virus infection. Optimizing protective responses while minimizing pathogenic responses are the goals for successful vaccines.

\section{Dengue vaccines}

The exponential rise in dengue virus infections over the past few decades has made the search for a dengue vaccine an imperative, but achieving this goal has proved enormously challenging. Any successful vaccine would need to induce a protective and durable immune response to all four dengue serotypes, preferably with one or two doses, in individuals who have been unexposed to dengue virus, as well as those who have had a previous dengue virus infection. At the same time, a vaccine would need to avoid eliciting or enhancing pathogenic immune responses.

As primary dengue virus infection does not give longterm protection to re-infection with the other three viral serotypes $^{79,80}$, it has been generally held that a vaccine will need to induce protective responses against all four serotypes, mandating a tetravalent formulation. Efforts to develop vaccines have been pursued for almost 50 years, beginning in Thailand with work to produce live attenuated viruses by serial passage of viral strains representative of the four serotypes ${ }^{81}$. A particular challenge has been to develop attenuated forms of the viruses that are not too virulent to induce overt dengue disease but are not too over-attenuated to be unable to incite a protective immune response. Another challenge has been to produce a tetravalent formulation in which all four viruses are delivered together, replicate equally and induce a balanced immune response against all four serotypes rather than resulting in good responses to some serotypes but poor responses to one or more serotypes ${ }^{82-84}$.

There have been substantial advances in recent years in vaccine development with three live attenuated vaccines currently undergoing clinical trials: CYD-tetravalent dengue vaccine (CYD-TDV), National Institutes of Health (NIH) live attenuated tetravalent vaccine (LATV) $\Delta 30$ and DENVax ${ }^{85-88}$ (FIG. 4). There are also 


\section{DENV1 infection}

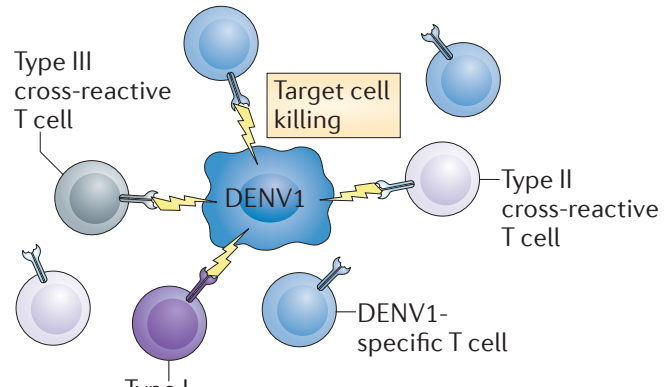

Type I

coss-reactive

T cell

b
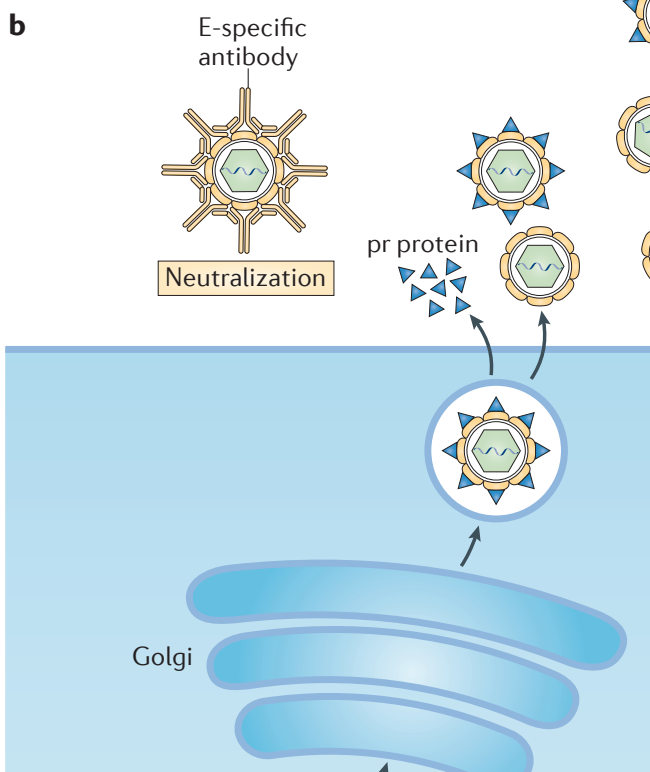

Golgi
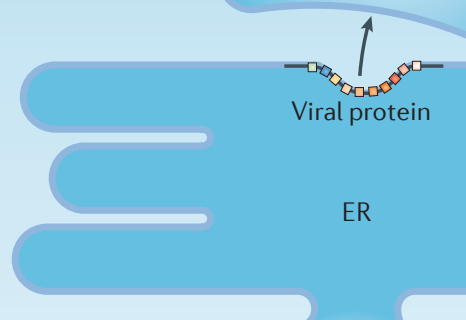

Dengue virusinfected cell

\section{c Neutralization}

Fully mature infectious dengue viral particle

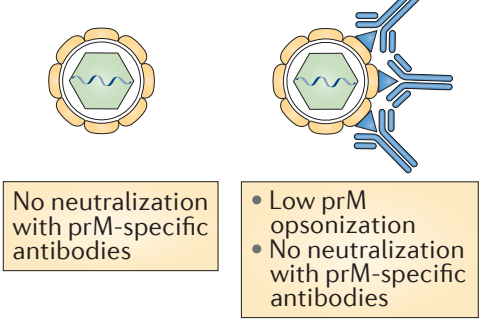

DENV1 infection followed by DENV2 infection

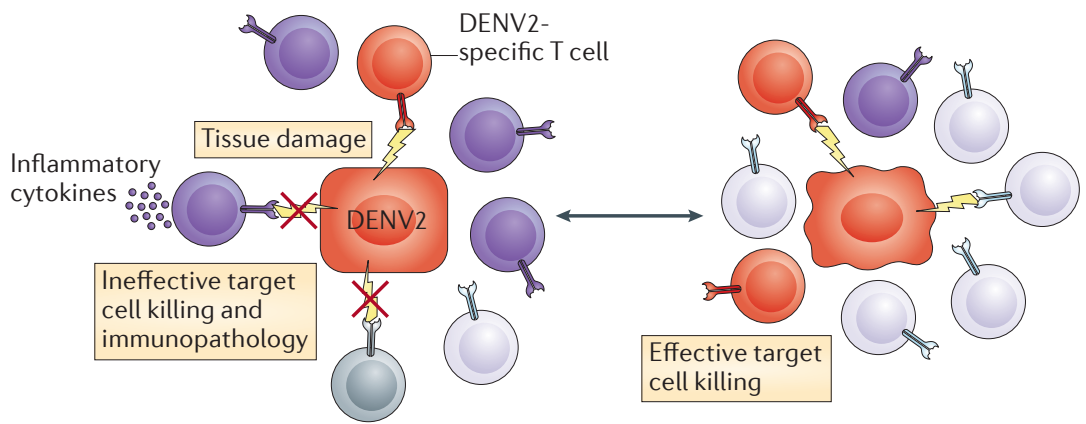

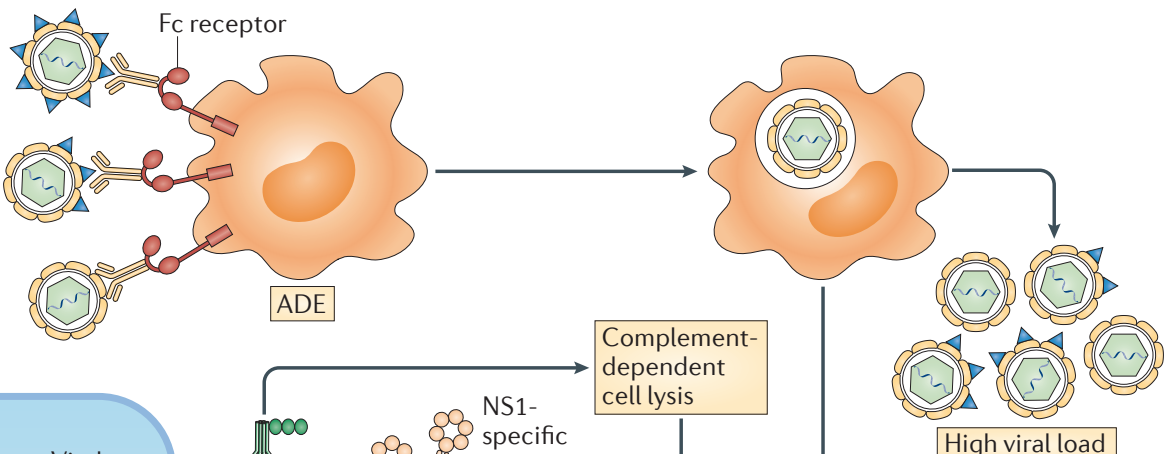

High viral load

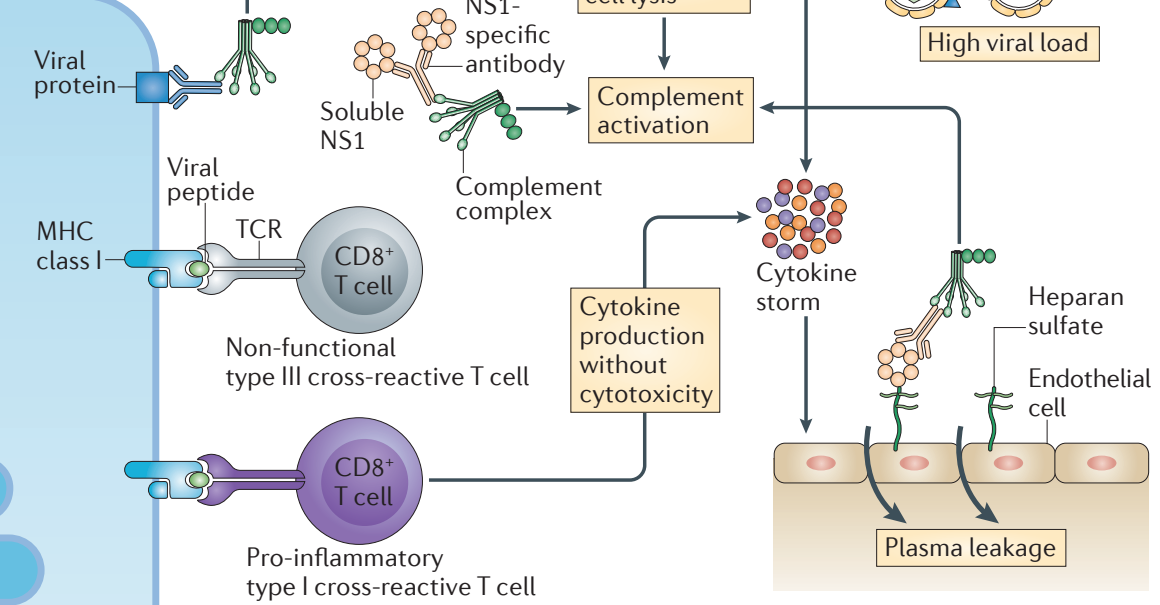

type I cross-reactive T cell

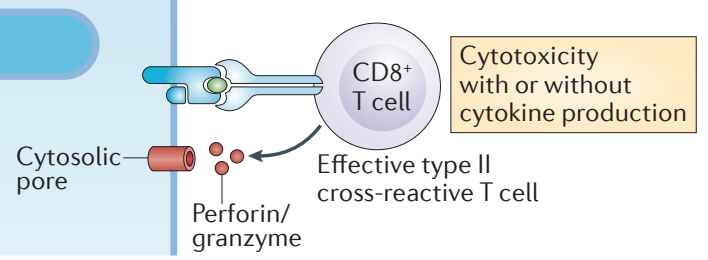

ADE

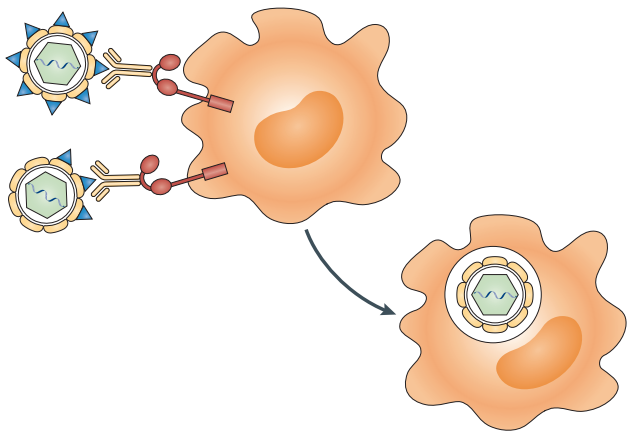


Heterologous prime-boost strategies

Vaccination strategies in which different immunogens are given sequentially to boost and focus an immune response achieved by utilizing a variety of platforms - viral, DNA or protein - with the same antigen being delivered sequentially. to a given antigen. This is

various other vaccines in preclinical studies. The most advanced in clinical trials is the Sanofi Pasteur vaccine CYD-TDV. This is a chimaera vaccine using the related yellow fever $17 \mathrm{D}$ vaccine strain as a backbone, with dengue virus prM protein and $\mathrm{E}$ protein genes replacing those from yellow fever virus. The vaccine contains a mixture of four recombinant viruses representing each serotype

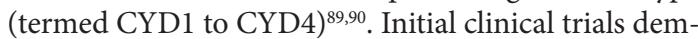
onstrated good serological responses to the vaccine, with seropositivity ranging from $66.5 \%$ to $100 \%^{91-93}$. However, the overall efficacy (that is, protection from infection) of a Phase IIb trial in Thailand was below expectations, with the lowest efficacy being against DENV2 (TABLE 1). Phase III trials of this vaccine in Asia and Latin America have been more promising; however, the results still showed suboptimal efficacy ranging from 35\% to $78 \%$ and, again, the efficacies against DENV2 were lowest ${ }^{94,95}$. Further analysis revealed that the vaccine gave better protection to vaccinees who were already immune to one or more serotypes before vaccination, and the protection offered by the vaccine against severe and haemorrhagic disease was between $80 \%$ and $91 \%{ }^{94,95}$.

\section{$\varangle$ Figure 3 | Adaptive immune responses to dengue virus infection. a|The} phenomenon of original antigenic sin occurs when memory $T$ cell activation in a second infection (for example, with dengue virus serotype 2 (DENV2) in middle and right panels) leads to the domination of that response by cross-reactive $T$ cells generated during a primary infection (for example, DENV1 in the left panel) with a different dengue virus serotype. Three types of cross-reactive T cells are illustrated: type I produce only inflammatory cytokines during secondary infection, type II can degranulate and potentially kill DENV2-infected target cells effectively, and type III cross-reactive T cells are of low avidity and can recognize DENV2-infected cells but do not induce a response. If there is a high proportion of type I cross-reactive T cells that are skewed to inflammatory cytokine production without cytotoxicity, it may predispose to immunopathology on secondary infection (middle panel), whereas if there is a predominance of type Il cells that can degranulate (right panel), the virus may be more rapidly cleared. $\mathbf{b} \mid$ The mixture of newly produced dengue virions can be neutralized by the optimum concentration of dengue virus-specific antibodies. In addition, dengue virus proteins - such as envelope (E) protein, precursor membrane (prM) protein and non-structural protein 1 (NS1) presented on the surface of dengue virus-infected cells, or soluble NS1, can be recognized by dengue virus-specific antibodies. These antibodies can promote complement-dependent cell lysis following complement activation by the classical pathway. Soluble NS1 can also bind to heparan sulfate, a major component of the endothelial glycocalyx layer that regulates capillary permeability. The subsequent recognition by NS1-specific antibodies triggers complement activation and anaphylatoxin formation, which may contribute to the disruption of this layer and vascular leak. Presentation of viral peptides on MHC class I or $\mathrm{MHC}$ class II molecules activates DENV-specific $\mathrm{CD} 8^{+} \mathrm{T}$ cells or $\mathrm{CD} 4^{+} \mathrm{T}$ cells, respectively. The recognition of $\mathrm{MHC}$-peptide complexes by DENV-specific T cells or effective type Il cross-reactive T cells (only cross-reactive $C D 8^{+} T$ cells are shown for simplicity) results in target cell lysis with or without cytokine production, whereas peptide recognition by ineffective DENV cross-reactive T cells (type I and type III) causes only cytokine production or no response. Sub-neutralizing concentrations of E- and/or prM-specific antibodies can bind to the dengue virus and mediate dengue virus infection of Fc receptor-expressing target cells, such as monocytes and macrophages, resulting in antibody-dependent enhancement (ADE) and increased viral load. The cytokines secreted by dengue virus-infected cells and those produced by T cells can be amplified by the high viral load and cause a cytokine storm and plasma leakage in patients infected with dengue virus. c | prM-specific antibodies show poor neutralization but are potent at inducing ADE. Fully mature particles contain no prM protein and will not be neutralized by prM-specific antibodies, whereas low-prM protein-containing particles do not contain enough prM protein for neutralization but can be opsonized for ADE. Some partially mature particles with higher levels of prM protein will be neutralized, whereas fully immature particles are non-infectious but can be made to infect cells via ADE. ER, endoplasmic reticulum; TCR, T cell receptor.
The first report from the long-term follow up of the CYD-TDV vaccine trials has recently been published ${ }^{96}$ and shows that older children in the vaccinated group (aged 9-16 years) continue to benefit. However, in the under-9-year age group, there appears to be an increase in hospitalization at 3 years post-vaccination when compared with control unvaccinated subjects ${ }^{96}$. This increase may represent disease enhancement, possibly by $\mathrm{ADE}$, in individuals who were uninfected at enrolment and who have been primed but not protected by the dengue vaccine. There is now much urgency in the field to understand why the initially promising in vitro correlates of vaccine immunity ${ }^{85,89-93}$ did not always translate to good in vivo efficacy ${ }^{94-96}$ and to develop more representative in vitro correlates of protection to inform future trials.

In the Phase IIb trial of CYD-TDV in Thailand, although the efficacy of the vaccine against DENV2 was low, the seropositivity to DENV2 at 1 year after vaccination was high ${ }^{90}$ (TABLE 1). Several reasons are postulated for this mismatch: first, the vaccine strain might be a poor immunological match for viral strains circulating during the study period, although preclinical trials showed that the vaccine candidate antigens induced neutralizing antibody activity against a broad range of viral strains ${ }^{85}$. Second, T cells may be important for protection, and because the CYD-TDV vaccine contains NS elements from yellow fever virus, it may not produce an effective dengue virus-specific T cell response. Third, the CYD-TDV vaccine does not contain dengue virus NS1, which was suggested to induce protective immunity in mouse models $s^{9798}$. Finally, the current plaque reduction neutralization test (PRNT), which uses viruses generated from cell lines, may not be a good surrogate for protection in vivo, and better, more predictive assays are urgently being sought.

The tetravalent formulation does not mimic the natural situation in which the vast majority of infections are with a single serotype followed by reinfection months to years later ${ }^{79,80}$. Although studying sequential infections in the population is difficult, surveillance studies suggest symptomatic cases caused by third or fourth infections are rare ${ }^{99-101}$. This implies that following secondary infection there is some degree of cross protection to the remaining serotypes. Inducing a balanced immune response to all four serotypes using a tetravalent formulation is clearly a major challenge, and heterologous prime-boost strategies have been suggested to overcome this. The observation in the recent Sanofi Pasteur trials that efficacy was better in individuals who had previously been exposed to dengue virus, compared with the uninfected cohort, may also be instructive in this regard, implying that the vaccine can boost pre-existing dengue virus immunity but is poor at producing a protective immune response de novo in dengue virus-naive vaccinees ${ }^{94}$.

Sequential priming and heterologous boosting with the recombinant viruses CYD1 to CYD4 has been investigated in primates ${ }^{102}$. CYD2 and CYD3 were inherently less immunogenic, with lower numbers of responders, than CYD1 and CYD4. Priming with CYD1 and CYD2 followed by boosting at day 56 with CYD3 and CYD4 gave better responses when compared with priming and boosting with the tetravalent vaccine, especially with 
a CYD-TDV (Sanofi Pasteur)

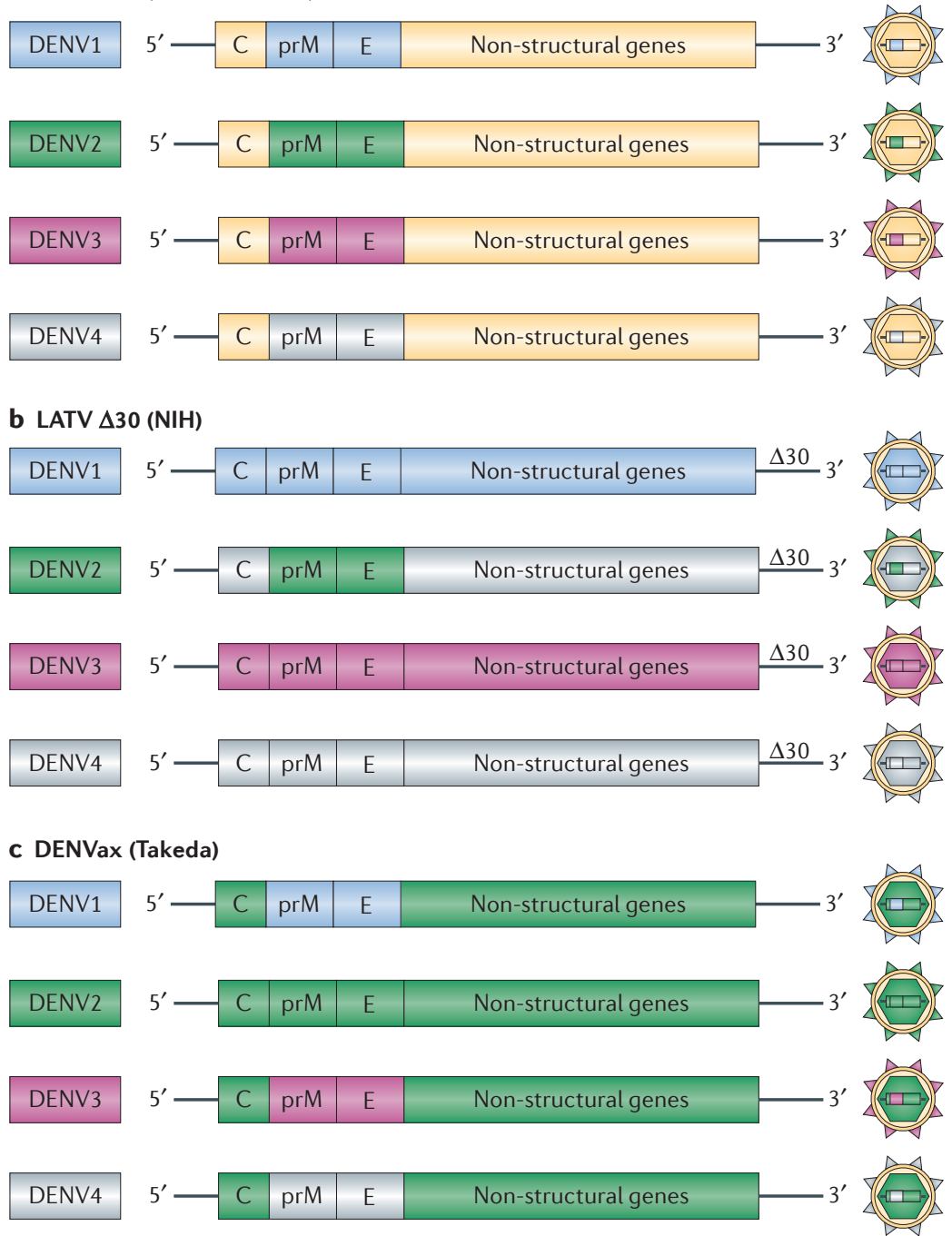

Figure 4 | Dengue vaccines. a | The Sanofi Pasteur vaccine CYD-TDV contains four chimeric live flaviviruses, each derived from the genome of the yellow fever virus 17D vaccine strain (shown in yellow) with the precursor membrane (prM) and envelope (E) gene segments replaced by the corresponding gene segments of each of the four dengue virus serotypes (DENV1 to DENV4). b | The US National Institutes of Health (NIH) live attenuated tetravalent vaccine (LATV) contains a mixture of four recombinant dengue virus genomes; the DENV2 component is a chimeric dengue virus derived from a DENV4 genome with prM and E gene segments replaced by those of DENV2. The vaccine strains were attenuated by deleting 30 nucleotides $(\Delta 30)$ from the $3^{\prime}$ untranslated region of the dengue viral genome. $\mathbf{c}$ The DENVax vaccine from Takeda contains a mixture of four recombinant DENV2 genomes, each derived from the genome of an attenuated DENV2 virus with prM and E gene segments replaced by the corresponding gene segments of DENV1, DENV3 and DENV4.

regard to responses to DENV2 (REF. 102). Heterologous priming and boosting has also been investigated in humans, in which CYD1 and CYD3 were used to prime and CYD2 and CYD4 used for boosting at 15 weeks ${ }^{103}$. In contrast to the primate study, the sequential bivalent immunization strategy was not superior to the repeated tetravalent immunization approach. It remains possible that the timing between priming and boosting and the serotype combinations used in these two studies may have influenced the outcome.
Of the other live attenuated vaccine candidates, a Phase I trial of the NIH LATV $\Delta 30$ vaccine, which has a 30-nucleotide deletion in the $3^{\prime}$ untranslated regions of the cloned cDNA (FIG. 4b), showed that seropositivity across all serotypes was over $90 \%$ after one dose of the vaccine; however, around $60 \%$ of vaccinees developed a rash and $73 \%$ experienced viraemia ${ }^{86,104}$. The tetravalent live attenuated vaccine DENVax (developed by Takeda) has undergone a Phase I trial ${ }^{87}$, in which more than half of the volunteers developed measurable antibodies to all four virus serotypes after a single dose $e^{87,105}$. Finally, despite the demonstration that the TDEN vaccine candidate developed by the Walter Reed Army Institute of Research (WRAIR) and GlaxoSmithKline induced antibody responses to the four serotypes in a Phase II trial, development has been stopped ${ }^{106}$.

Despite the difficulties, there remains a pressing need to pursue vaccine candidates as well as to test whether live attenuated vaccines can be improved to provide a more balanced protection, and whether these responses are durable will be determined by longer-term follow up of clinical trials.

\section{New insights from monoclonal antibodies}

A large number of mouse antibodies have been generated against dengue virus, and the epitopes for several of these have been mapped by systematic or random mutagenesis to the E protein ${ }^{107-116}$. More recently, human $\mathrm{mAbs}$ have been generated from dengue virus-infected patients; the main epitopes recognized by mAbs are described in this section (TABLE 2).

Antibodies targeting the fusion loop epitope of E protein. The fusion loop epitope (FLE) is a major epitope targeted by antibodies produced in both humans and mice. mAbs specific for the FLE are exemplified by mAb E53, which was originally isolated from West Nile virus-infected mice but is fully cross-reactive with dengue viruses ${ }^{117}$. Mutation of E protein W101 blocks the binding of antibodies directed to the FLE and reduces the reactivity of polyclonal human serum ${ }^{118-120}$. mAbs specific for FLE show good neutralization of dengue viruses grown in insect cells, which contain high levels of prM protein ${ }^{16}$. FLEspecific $\mathrm{mAbs}$ bind better in the presence of prM protein which, by virtue of changing the virion architecture, better exposes the FLE ${ }^{13}$. The binding of FLE-specific mAbs to more mature virions produced in primary human cells, which contain lower levels of prM protein, and their subsequent neutralization is not particularly efficient, with neutralization levels typically failing to exceed $60-80 \%$ even at high antibody concentrations ${ }^{16}$. The induction of antibodies specific for FLE, although commonly generated in humans and often cross-reactive between serotypes, may not therefore be the ideal response to target by vaccines. Another antibody, 1C19, which recognizes the BC loop (amino acids 73, 78 and 79) close to the FLE, potently neutralized all four serotypes, suggesting that the epitope may be a good target for vaccines. However, it is not clear whether the epitope for 1C19 is prM-dependent in common with other FLE-specific mAbs, as the epitope for 1C19 lies close to the FLE ${ }^{121}$. 
Table 1 | Dengue vaccine candidates

\begin{tabular}{|c|c|c|c|c|c|c|c|}
\hline $\begin{array}{l}\text { Vaccine } \\
\text { candidate }^{*}\end{array}$ & Phase & $\begin{array}{l}\text { Trial } \\
\text { Geographical } \\
\text { region }\end{array}$ & $\begin{array}{l}\text { Age of } \\
\text { vaccinee }\end{array}$ & Trial design & Results $^{\ddagger}$ & Side effects & Refs \\
\hline $\begin{array}{l}\text { CYD-TDV } \\
\text { (Sanofi } \\
\text { Pasteur) }\end{array}$ & $\begin{array}{l}\text { Phase III } \\
(N=20,869)\end{array}$ & Latin America & $9-16$ years & $\begin{array}{l}\text { - Vaccination at } 0,6 \text { and } \\
12 \text { months } \\
\text { - Follow up } 25 \text { months } \\
\text { after final vaccination } \\
\text { - Incidence density of } \\
\text { dengue: } 2.9 \% \text { per year }\end{array}$ & $\begin{array}{l}\text { - Overall efficacy: } 60.8 \% \\
\text { - Efficacy: } 50.3 \% \text { against } \\
\text { DENV1; } 42.3 \% \text { against DENV2; } \\
\text { 74.0\% against DENV3; } 77.0 \% \\
\text { against DENV4 } \\
\text { - Seropositivity at baseline: } 83.7 \% \\
\text { - Seronegativity at baseline: } 43.2 \% \\
\text { - Protection from severe } \\
\text { disease: } 91.7 \% \text {; protection } \\
\text { from DHF: } 90 \%\end{array}$ & $\begin{array}{l}\text { - Four SAEs: } \\
\text { asthma, urticarial, } \\
\text { acute peripheral } \\
\text { polyneuropathy } \\
\text { and viral } \\
\text { meningitis } \\
\text { - Seizure } \\
\text { - No long-term } \\
\text { sequelae }\end{array}$ & 94 \\
\hline $\begin{array}{l}\text { CYD-TDV } \\
\text { (Sanofi } \\
\text { Pasteur) }\end{array}$ & $\begin{array}{l}\text { Phase III } \\
(N=10,275)\end{array}$ & Asia Pacific & 2-14 years & $\begin{array}{l}\text { - Vaccination at } 0,6 \text { and } \\
12 \text { months } \\
\text { - Follow up } 25 \text { months } \\
\text { after final vaccination } \\
\text { - Incidence density of } \\
\text { dengue: } 4.7 \% \text { per year }\end{array}$ & $\begin{array}{l}\text { - Overall efficacy: } 56.5 \% \\
\text { - Efficacy in } 2-5 \text { years old: } \\
\text { 33.7\%; 6-11 years old: } 59.5 \% \text {; } \\
\text { 12-14 years old: } 74.4 \% \\
\text { - Efficacy: } 50.0 \% \text { against } \\
\text { DENV1; 35.0\% against DENV2; } \\
\text { 78.4\% against DENV3, 75.3\% } \\
\text { against DENV4 } \\
\text { - Seropositivity at baseline: } \\
\text { 74.3\% } \\
\text { Seronegativity at baseline: } \\
\text { 35.5\% } \\
\text { Protection from severe } \\
\text { disease: } 80.8 \% \text {; protection } \\
\text { from DHF: } 88.5 \%\end{array}$ & $\begin{array}{l}\text { - One SAE: acute } \\
\text { disseminated } \\
\text { encephalomyelitis } \\
\text { - No long-term } \\
\text { sequelae }\end{array}$ & 95 \\
\hline $\begin{array}{l}\text { CYD-TDV } \\
\text { (Sanofi } \\
\text { Pasteur) }\end{array}$ & $\begin{array}{l}\text { Phase Ilb } \\
(N=4,002)\end{array}$ & Thailand & 4-11 years & $\begin{array}{l}\text { - Vaccination at } 0,6 \text { and } \\
12 \text { months } \\
\text { - Follow up } 25 \text { months } \\
\text { after final vaccination }\end{array}$ & $\begin{array}{l}\text { - Overall efficacy } 30.2 \% \\
\text { Efficacy against DENV1 55.6\%, } \\
\text { DENV2 9.2\%, DENV3 } 75.3 \% \text {, } \\
\text { DENV4 100\% } \\
\text { Seropositivity } 1 \text { year after third } \\
\text { dose: DENV1 77\%, DENV2 } \\
\text { 85\%, DENV3 89\%, DENV4 94\% }\end{array}$ & $\begin{array}{l}\text { No attributable } \\
\text { SAE }\end{array}$ & 90 \\
\hline $\begin{array}{l}\text { TDEN } \\
\text { (WRAIR } \\
\text { and GSK) }\end{array}$ & $\begin{array}{l}\text { Phase II } \\
(N=120)\end{array}$ & Thailand & $20-24$ years & $\begin{array}{l}\text { - Vaccination at } 0 \text { and } \\
6 \text { months } \\
\text { - Compared placebo to } \\
\text { two formulations: F17 } \\
\text { and F19 } \\
\text { - Follow up } 31 \text { days after } \\
\text { final vaccination }\end{array}$ & $\begin{array}{l}\text { Seropositivity pre-vaccination: } \\
\text { 76.5\% (F17) and } 78.9 \% \text { (F19) to } \\
\text { all four serotypes } \\
\text { Seropositivity } \\
\text { post-vaccination: } 97.1 \% \text { F17 } \\
\text { and } 100 \% \text { F19 to all four } \\
\text { serotypes }\end{array}$ & $\begin{array}{l}\text { Viraemia in } 5 \text { of } 80 \\
\text { vaccinees } \\
\text { - Rash on }>50 \% \text { of } \\
\text { body area in } 5 \% \text { of } \\
\text { vaccinees }\end{array}$ & 88 \\
\hline $\begin{array}{l}\text { LATV } \Delta 30 \\
(\mathrm{NIH})^{\S}\end{array}$ & $\begin{array}{l}\text { Phase I } \\
(N=113)\end{array}$ & USA & $18-50$ years & $\begin{array}{l}\text { - Single dose of four } \\
\text { different admixtures } \\
\text { tested (TV001 to TV004) } \\
\text { - Vaccinees were } \\
\text { flavivirus-naive }\end{array}$ & $\begin{array}{l}\text { TV003 was the best formula } \\
\text { with } 45 \% \text { of vaccinees with } \\
\text { neutralizing antibodies against } \\
\text { all four serotypes }\end{array}$ & $\begin{array}{l}\text { Viraemia in } 73 \% \\
\text { of vaccinees } \\
\text { - Rash in } 64.2 \% \text { of } \\
\text { vaccinees }\end{array}$ & 104 \\
\hline $\begin{array}{l}\text { DENVax } \\
(\text { Takeda) }\end{array}$ & $\begin{array}{l}\text { Phase I } \\
(N=96)\end{array}$ & Colombia & $18-45$ years & $\begin{array}{l}\text { - Comparison of } \\
\text { placebo versus low and } \\
\text { high dose of DENVax } \\
\text { and intradermal } \\
\text { versus subcutaneous } \\
\text { administration } \\
\text { - Dengue- and yellow } \\
\text { fever-naive volunteers }\end{array}$ & $\begin{array}{l}\text { 71\% seroconverted to all four } \\
\text { serotypes in the intradermal } \\
\text { group } \\
\text { - Neutralizing antibody levels to } \\
\text { DENV2 were highest }\end{array}$ & $\begin{array}{l}\text { - No SAE } \\
\text { rangerall viraemia } \\
\text { (low dose) to } 85 \% \\
\text { (high dose) }\end{array}$ & 87 \\
\hline
\end{tabular}

DENV, dengue virus serotype; DHF, dengue haemorrhagic fever; E protein, envelope protein; GSK, GlaxoSmithKline; LATV, live attenuated tetravalent vaccine; $\mathrm{NIH}$, National Institutes of Health; NMRC, National Medical Research Council; prM, precursor membrane; SAE, serious adverse event; WRAIR, Walter Reed Army Institute of Research. *Soluble E protein (Merck), purified inactivated virus (WRAIR) and DNA-expressing prM protein and E protein (NMRC) vaccine candidates are in Phase I clinical trials. " Efficacy is expressed in \% with a 95\% confidential interval. ${ }^{\S}$ Under Phase II trial.

E protein domain III. Antibodies targeting EDIII have been frequently isolated from mice ${ }^{71}$ and are among the most potent antibodies described to dengue virus, with $50 \%$ in vitro neutralization (NT50) levels at concentrations in the low picomolar range $\mathrm{e}^{71,107-110,112-115}$. These antibodies are frequently specific for a single dengue virus serotype, although the EDIII-binding mAb 4E11 has been engineered to bind to and potently neutralize all four dengue virus serotypes ${ }^{122}$. The epitopes for some EDIII-binding mAbs have been mapped in detail by mutagenesis, crystallography and cryo-EM. The mAb E16 binds West Nile virus, a flavivirus related 
Table 2 | Characteristics of human monoclonal antibodies

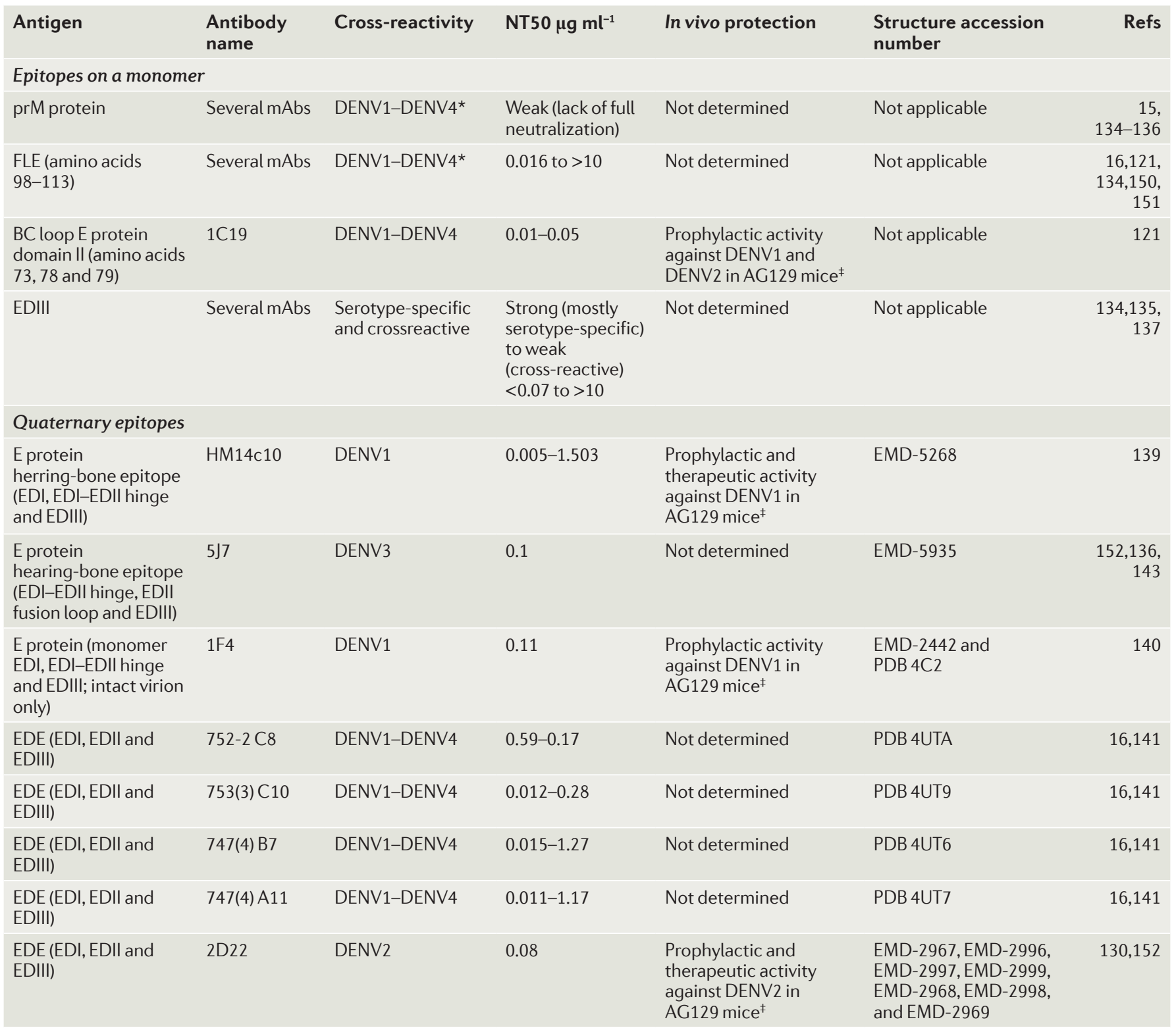

DENV, dengue virus serotype; ED, envelope protein domain; EDE, envelope protein dimer epitope; E protein, envelope protein; FLE, fusion loop epitope; $\mathrm{mAb}$, monoclonal antibody. ${ }^{\star} \mathrm{A}$ majority of antibodies in this group recognise all 4 dengue virus serotypes. ${ }^{\ddagger}$ Mice that lack type I and type II interferon receptors.

to dengue virus, where the epitope lies on the lateral ridge of EDIII ${ }^{71}$. Although not binding to dengue virus, E16 defines a class of antibodies binding to the lateral ridge of EDIII and shows potent neutralization of West Nile virus in vitro and in vivo in both prophylactic and therapeutic settings ${ }^{123}$. Another EDIII-specific antibody, 1A1D2, binds to the A strand (amino acids 305-312) of dengue virus EDIII ${ }^{124}$. In contrast to the lateral ridge of EDIII, the A strand is more conserved among the dengue viruses, allowing 1A1D2 to cross-react between DENV1, DENV2 and DENV3 (REF. 111).

Interestingly, the epitope recognized by $1 \mathrm{~A} 1 \mathrm{D} 2$ is not fully exposed in the smooth mature form of the dengue virion, and cryo-EM has shown that a temperaturedependent conformational change allows EDIII to hinge up from its flat orientation in the smooth mature virion and facilitates mAb 1A1D2 binding ${ }^{124}$. Because of the potency of the EDIII-specific $\mathrm{mAb}$ and the general serotype specificity of the response, EDIII has been proposed as a potential immunogen in a variety of vaccine formulations. However, the contribution of EDIII to the human antibody response appears to be more limited; it has been shown that the depletion of EDIII-specific antibodies from human serum does not reduce its neutralization potential in vitro and in vivo ${ }^{77,125}$.

prM protein and virus maturity. As described above, immature dengue virus particles contain prM protein, which acts as a chaperone for E protein and prevents premature fusion to host cell membranes before virus release. 
prM protein is cleaved by furin protease in the Golgi and falls away when mature virus particles are released from cell $^{4,7,10}$. However, prM cleavage is frequently incomplete, with a range of partially mature virus forms produced with intermediate levels of prM protein ${ }^{11}$. This produces a challenge for the host immune response, as mature and immature virus particles present markedly different structural determinants at the virion surface. Studies of primary human cells infected with dengue virus suggest that, following an insect bite, the human host is first infected by viruses that have a high prM content; however, viruses produced in human cells will have potentially lower prM content, although the prM content of dengue virus in ex vivo samples has not been measured ${ }^{15,16}$. Several dengue virus-specific antibodies, such as those targeting the FLE or prM protein, lack the ability to neutralize more mature, low-prM protein viruses ${ }^{15,16}$.

Alternative conformations of the virion surface. The binding of antibodies to viruses is a complex process, in which the packing of $\mathrm{E}$ protein and prM protein into the virion lattice affects the accessibility of the target epitopes to antibodies. Several antibodies that bind well to recombinant monomeric E protein fail to show good binding or neutralization of intact virions because the viral epitopes are poorly exposed ${ }^{14,17,71,124,126}$. The binding of such antibodies may be enhanced by the prM protein content of the virions, as described above for the FLE-specific antibodies, but may also be enhanced in vitro by prolonged incubation periods or increased temperature ${ }^{127}$. This has led to the proposition that the traditional view of the virion as an invariant or rigid, smooth or spiky entity (which is necessarily imposed by the solution of cryo-EM structures) is not accurate. Instead, it is proposed that the virion is a dynamic entity that is capable of adopting many different conformations with different thermodynamic stabilities, which is often referred to as virion breathing ${ }^{124,128,129}$. In this regard, an alternative 'bumpy' form of DENV2 particles has been recently described, in which there is disruption of the regular packing of the E protein dimers at the virion surface at $37^{\circ} \mathrm{C}^{128,129}$. This has implications for antibody binding, as shown by cryo-EM structures of mAb 2D22 binding to DENV2 particles, in which the valency of binding to the bumpy form of the virus was lower than that to the more regular form ${ }^{130}$. The display of an 'ensemble' of different E protein and virion conformations can be continuously sampled and captured by antibodies, explaining the increase in binding of antibodies to dengue virus particles in a temperature- and time-dependent manner ${ }^{12,127}$.

Human mAbs. The study of antibody responses in humans has been revolutionized by the development of various techniques that have allowed the generation of large numbers of human mAbs. Three main techniques have been used: expansion and Epstein-Barr virus immortalization of memory B cells; single-cell sorting, cDNA cloning and antibody expression from plasmablasts isolated from acutely infected individuals; and optimization by electrofusion of traditional hybridoma technology to make antibodies from memory B cells ${ }^{131-133}$.
Antibodies to prM protein. prM protein-specific antibodies appear to be a major component of the memory $\mathrm{B}$ cell response to dengue virus infection; however, these antibodies show poor neutralization (maximum 30-50\%) even at high concentrations ${ }^{15,134-137}$. prM protein-specific antibodies do not bind to fully mature virions as they lack prM protein, and many partially mature particles do not contain a high enough density of prM protein to allow neutralization; furthermore, they may be sufficient to promote $\mathrm{ADE}^{15,18}$. We have speculated that the inefficient cleavage of prM protein may be an immune evasion strategy, leading to the generation of poorly neutralizing antibodies directed to prM protein, as well as to the FLE, which also form a major component of the human antibody response ${ }^{15,16,118}$.

The high frequency, low potency and high ADE potential of antibodies directed to prM protein have implications for vaccine design. All attenuated vaccines at an advanced stage of development contain prM protein, whereas the ideal vaccine would focus responses to the E protein and minimize the prM protein component of the response to reduce the potential for ADE. One possible route to this would be the generation of attenuated chimeric viruses with prM protein derived from third party flaviviruses such as Japanese encephalitis or West Nile virus, in which the anti-prM protein response cross-reacts poorly with dengue virus ${ }^{15,138}$.

Antibodies targeting quaternary epitopes on the virion. Some of the most potent human antibodies bind to conformational and quaternary determinants that are only reproduced on intact dengue virions ${ }^{16,130,139-141}$. One well-characterized epitope, the so-called 'herringbone epitope', has been described by cryo-EM for the DENV1-specific mAb HM14c10 (REF. 139). This antibody binds to an epitope that bridges between two adjacent head-to-tail E protein dimers, which form a herringbone-like conformation on the mature virion (FIG. 5a). Several other conformationally sensitive antibodies have been mapped by cryo-EM; the DENV1-specific mAb $1 F 4$ binds to a single E protein monomer, but only in the context of the virion, whereas the DENV3-specific $\mathrm{mAb}$ $5 \mathrm{~J} 7$ binds across three adjacent $\mathrm{E}$ protein monomers with a major component of the interaction across the hinge between EDI and EDII of the central E protein monomer ${ }^{140,143}$. These conformational antibodies show potent neutralization but are nevertheless serotype specific.

We have recently described the cloning of a large series of $\mathrm{E}$ protein-specific $\mathrm{mAbs}$ from patients infected with dengue virus ${ }^{16}$. One-third of the antibodies bind to a complex epitope present only on intact virions. Interestingly, although most of the panel of human antibodies showed good neutralization of high-prM protein viruses produced in insect cells, only binding of mAbs to the complex epitope on intact virions could fully neutralize low-prM protein virions produced in primary human cells.

These broadly neutralizing antibodies bind to the basic repeating E protein dimers that make up the virion surface lattice, and the epitope is termed the E protein dimer epitope (EDE) $)^{16,141}$ (FIG. 5b,c). The antibodies bind 

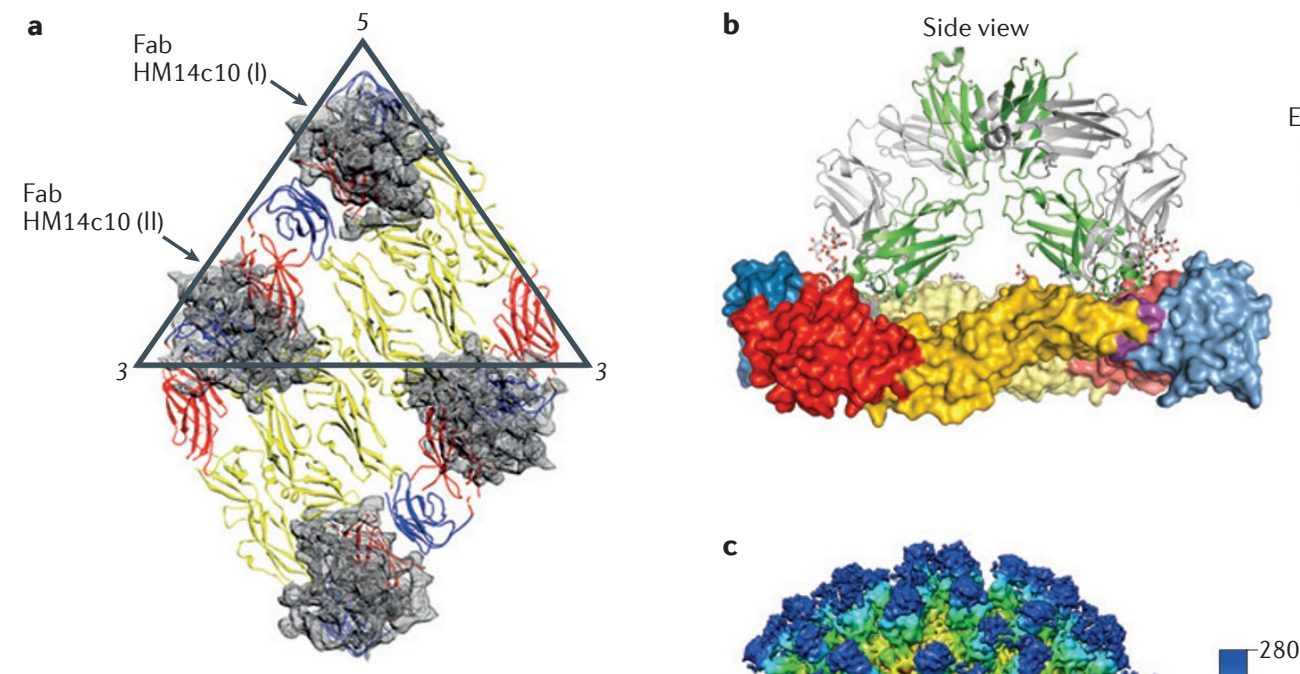

Top view
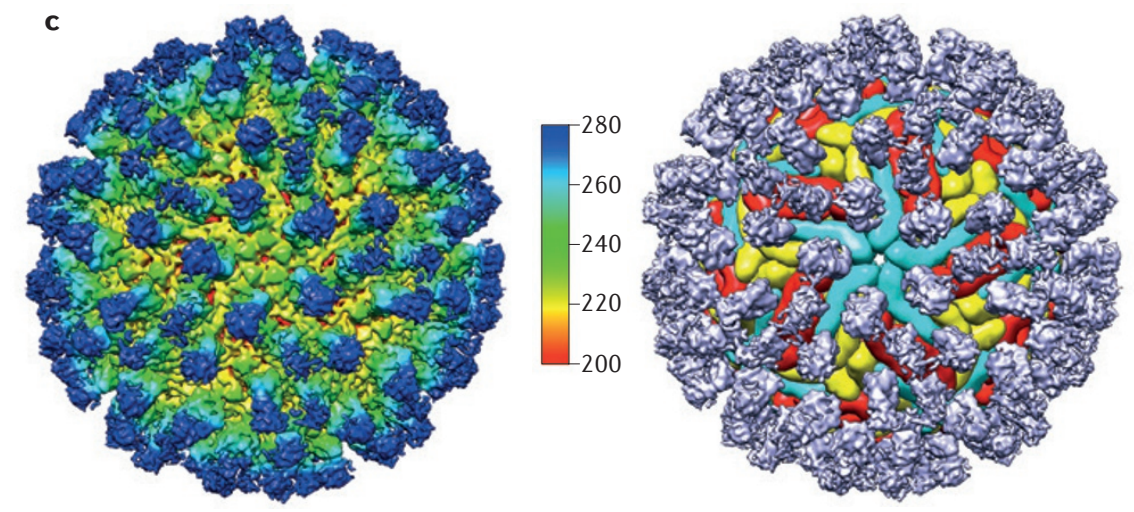

Figure 5 | Quaternary epitopes. The cryo-electron microscopy (cryo-EM) structure shows where HM14c10 binds to the epitope between two envelope (E) protein monomers of adjacent dimers (part a). The structure (part b) and the cryo-EM reconstruction (part c) of the DENV2 particle in complex with an E protein dimer epitope (EDE)-specific monoclonal antibody (mAb) - 747(4) A11 and 747(4) B7 for part b and part c, respectively — demonstrate that the epitope of the antibody is across two E proteins within one dimer. The colour scale in part $\mathbf{c}$ indicates the radial depth from inside (red) to the outer shell (yellow, green and blue). Domains I, II and III of the E protein (EDI-EDIII) are indicated in red, yellow and blue, respectively. In part $\mathbf{b}$ top view, the green outline shows the footprint of the EDE-specific mAb. Figure in part a from Teoh, E. P. et al. The structural basis for serotype-specific neutralization of dengue virus by a human antibody. Sci. Transl. Med. 4, 139ra83 (2012). Reprinted with permission from AAAS. Figure in part b from REF. 141 , Nature Publishing Group. Figure in part c from REF. 16, Nature Publishing Group.

in a valley formed between the two monomers of $\mathrm{E}$ protein, making up the 90 head-to-tail dimers of the virion, and overlap with the footprint on E protein where prM protein sits on the immature dengue virus particle. The antibodies make contact with several conserved amino acid side chains and main chain atoms in the E protein peptide backbone, which explains the cross-reactivity and broad neutralization of the four virus serotypes by these antibodies. Another recently reported $\mathrm{mAb}$, $2 \mathrm{D} 22$, binds to E dimers, although the epitope is slightly shifted towards EDIII compared with the epitope described above, which results in 2D22 being specific for just DENV2 and not broadly cross-reactive ${ }^{130}$.

The discovery of the EDE opens up a number of interesting future possibilities for dengue treatment. Current vaccination strategies use tetravalent formulations with the aim of raising single serotype-specific responses against all four serotypes. The demonstration that potent and broadly neutralizing antibodies are produced during dengue virus infection indicates that the development of such antibodies should be a goal for the next-generation vaccines. Furthermore, it may be possible to design a universal, rather than tetravalent, formulation to achieve this response or to use heterologous prime-boost strategies. Importantly, as the response is limited to the E protein dimer, it opens the way for subunit vaccines that consist of $\mathrm{E}$ protein dimers alone. To achieve this, the $\mathrm{E}$ protein dimer will need to be stabilized, as E protein only forms dimers naturally at relatively high protein concentrations. A similar situation has been observed with respiratory syncytial virus, in which potent neutralizing antibodies bind to the trimeric pre-fusion forms of the fusion protein (F protein) ${ }^{144}$. Efforts to stabilize a soluble $\mathrm{F}$ protein trimer have been successful either by cavity-filling hydrophobic substitution or by covalent linkage of the F protein monomer, which allows for the generation of a novel subunit immunogen that is capable of inducing a neutralizing response against the $\mathrm{F}$ protein trimer in mouse and primate models of respiratory syncytial virus infection ${ }^{145}$.

As described here, the neutralization of dengue viruses is a complex process with several different virion forms produced during infection. Successful vaccines need to target potently neutralizing epitopes, such as those found on EDIII or quaternary epitopes, and minimize the targeting of poorly neutralizing epitopes, such as those on PrM protein or the FLE. 


\section{Conclusion and future direction}

Despite nearly 50 years of work, we still do not have a fully efficacious dengue virus vaccine, and it remains to be determined whether the Sanofi Pasteur CYD-TDV live attenuated vaccine will be licensed and deployed in endemic countries. However, the burden of dengue continues to increase and, despite promising advances in vector control strategies and an increasingly active search for antiviral drugs that target dengue virus, an effective vaccine is seen by many as the only realistic strategy to control the spread of this disease and reduce the burden it has on the health-care systems in endemic countries.

There are a number of second-generation live attenuated vaccines that are approaching larger-scale clinical trials. The challenge of inducing protection against all four virus serotypes using a tetravalent formulation is formidable, and heterologous prime-boost strategies, which mimic natural infection but have given conflicting results, may need to be evaluated further. The recent description of potent human neutralizing antibodies in dengue gives insight into the sort of responses that should be targeted by vaccines. However, major challenges in how to preferentially boost immune responses to these complex quaternary epitopes remain. Finally, the recent Sanofi Pasteur clinical trials have demonstrated the need for robust in vitro correlates of protection, which would guide the development of future vaccine trials, and there is now interest in developing dengue virus-challenge studies in humans to guide future vaccine development.
1. Bhatt, S. et al. The global distribution and burden of dengue. Nature 496, 504-507 (2013).

2. Simmons, C. P., Farrar, J. J., Nguyen v, V. $\&$ Wills, B. Dengue. N. Engl. J. Med. 366, 1423-1432 (2012)

3. Kuhn, R. J. et al. Structure of dengue virus: implications for flavivirus organization, maturation, and fusion. Cell 108, 717-725 (2002).

This study shows the first structure of a mature flavivirus; the dengue virion is shown to consist of $90 \mathrm{E}$ protein dimers arranged into a smooth virus particle.

4. Li, L. et al. The flavivirus precursor membraneenvelope protein complex: structure and maturation. Science 319, 1830-1834 (2008).

This is an important study demonstrating the structure and linkage of the prM protein to the $E$ protein.

5. Modis, Y., Ogata, S., Clements, D. \& Harrison, S. C. A ligand-binding pocket in the dengue virus envelope glycoprotein. Proc. Natl Acad. Sci. USA 100 6986-6991 (2003).

6. Modis, Y., Ogata, S., Clements, D. \& Harrison, S. C. Structure of the dengue virus envelope protein after membrane fusion. Nature 427, 313-319 (2004).

This study shows how the structure of dengue $E$ protein changes from dimer to trimer after membrane fusion.

7. Yu, I. M. et al. Structure of the immature dengue virus at low $\mathrm{pH}$ primes proteolytic maturation. Science 319, 1834-1837 (2008).

8. Zhang, Y. et al. Structures of immature flavivirus particles. EMBO J. 22, 2604-2613 (2003).

This study describes how the arrangement of prM protein and E protein leads to the formation of the spiky trimers on immature dengue virions.

9. Zhang, Y. et al. Conformational changes of the flavivirus E glycoprotein. Structure 12, 1607-1618 (2004).

10. Mukhopadhyay, S., Kuhn, R. J. \& Rossmann, M. G. A structural perspective of the flavivirus life cycle. Nat. Rev. Microbiol. 3, 13-22 (2005).

11. Junjhon, J. et al. Influence of pr-M cleavage on the heterogeneity of extracellular dengue virus particles. J. Virol. 84, 8353-8358 (2010)

12. Dowd, K. A., Mukherjee, S., Kuhn, R. J. \& Pierson, T. C. Combined effects of the structural heterogeneity and dynamics of flaviviruses on antibody recognition. J. Virol. 88, 11726-11737 (2014).

13. Cherrier, M. V. et al. Structural basis for the preferential recognition of immature flaviviruses by a fusion-loop antibody. EMBO J. 28, 3269-3276 (2009).

14. Mukherjee, S. et al. Mechanism and significance of cell type-dependent neutralization of flaviviruses. J. Virol. 88, 7210-7220 (2014).

15. Dejnirattisai, W. et al. Cross-reacting antibodies enhance dengue virus infection in humans. Science 328, 745-748 (2010). This study reveals that there is a high proportion of prM-specific antibodies among human mAbs, and these antibodies do not effectively neutralize dengue virus but instead potently enhance the infection (that is, ADE).
16. Dejnirattisai, W. et al. A new class of highly potent, broadly neutralizing antibodies isolated from viremic patients infected with dengue virus. Nat. Immunol. 16, 170-177 (2015).

This study describes mAbs directed against a previously unknown epitope, the EDE; these mAbs are broadly neutralizing across dengue serotypes.

17. Heinz, F. X et al. Structural changes and functional control of the tick-borne encephalitis virus glycoprotein E by the heterodimeric association with protein prM. Virology 198, 109-117 (1994).

18. Rodenhuis-Zybert, I. A. et al. Immature dengue virus: a veiled pathogen? PLoS Pathog. 6, e1000718 (2010)

19. Plevka, P. et al. Maturation of flaviviruses starts from one or more icosahedrally independent nucleation centres. EMBO Rep. 12, 602-606 (2011).

20. Cruz-Oliveira, C. et al. Receptors and routes of dengue virus entry into the host cells. FEMS Microbiol. Rev. 39, 155-170 (2015).

21. Halstead, S. B. et al. Observations related to pathogenesis of dengue hemorrhagic fever. I. Experience with classification of dengue viruses. Yale J. Biol. Med. 42, 261-275 (1970).

22. Sangkawibha, N. et al. Risk factors in dengue shock syndrome: a prospective epidemiologic study in Rayong, Thailand. I. The 1980 outbreak. Am. J. Epidemiol. 120, 653-669 (1984).

23. Avirutnan, P. et al. Vascular leakage in severe dengue virus infections: a potential role for the nonstructural viral protein NS1 and complement. J. Infect. Dis. 193 1078-1088 (2006)

24. Libraty, D. H. et al. Differing influences of virus burden and immune activation on disease severity in secondary dengue-3 virus infections. J. Infect. Dis. 185, 1213-1221 (2002)

25. Libraty, D. H. et al. High circulating levels of the dengue virus nonstructural protein NS1 early in dengue illness correlate with the development of dengue hemorrhagic fever. J. Infect. Dis. 186 1165-1168 (2002)

26. Rothman, A. L. Immunity to dengue virus: a tale of original antigenic sin and tropical cytokine storms. Nat Rev. Immunol. 11, 532-543 (2011).

27. Nguyen, T. H. et al. Dengue hemorrhagic fever in infants: a study of clinical and cytokine profiles. J. Infect. Dis. 189, 221-232 (2004).

28. Dejnirattisai, W. et al. A complex interplay among virus, dendritic cells, $\mathrm{T}$ cells, and cytokines in dengue virus infections. J. Immunol. 181, 5865-5874 (2008)

29. Green, S. et al. Early immune activation in acute dengue illness is related to development of plasma leakage and disease severity. J. Infect. Dis. 179 , 755-762 (1999).

30. Bethell, D. B. et al. Pathophysiologic and prognostic role of cytokines in dengue hemorrhagic fever. J. Infect. Dis. 177, 778-782 (1998).

31. Ferrara, J. L., Abhyankar, S. \& Gilliland, D. G Cytokine storm of graft-versus-host disease: a critical effector role for interleukin-1. Transplant Proc. 25 1216-1217 (1993)

32. Ramachandran, G. Gram-positive and gram-negative bacterial toxins in sepsis: a brief review. Virulence 5, 213-218 (2014).
33. de Jong, M. D. et al. Fatal outcome of human influenza A (H5N1) is associated with high viral load and hypercytokinemia. Nat. Med. 12, 1203-1207 (2006).

34. Chen, Y. et al. Dengue virus infectivity depends on envelope protein binding to target cell heparan sulfate. Nat. Med. 3, 866-871 (1997).

35. Avirutnan, P. et al. Secreted NS1 of dengue virus attaches to the surface of cells via interactions with heparan sulfate and chondroitin sulfate $\mathrm{E}$. PLoS Pathog. 3, e183 (2007).

36. Avirutnan, P. et al. Antagonism of the complement component $\mathrm{C} 4$ by flavivirus nonstructural protein NS1. J. Exp. Med. 207, 793-806 (2010).

37. St John, A. L. Influence of mast cells on dengue protective immunity and immune pathology. PLoS Pathog. 9, e1003783 (2013).

38. Rothman, A. L. Dengue: defining protective versus pathologic immunity. J. Clin . Invest 113, 946-951 (2004).

39. Duangchinda, T. et al. Immunodominant T-cel responses to dengue virus NS3 are associated with DHF. Proc. Natl Acad. Sci. USA 107, 16922-16927 (2010).

40. Kurane, I., Zeng, L., Brinton, M. A. \& Ennis, F. A. Definition of an epitope on NS3 recognized by human CD4 ${ }^{+}$cytotoxic T lymphocyte clones cross-reactive for dengue virus types 2, 3, and 4. Virology 240, 169-174 (1998)

41. Livingston, P. G. et al. Dengue virus-specific, HLA-B35-restricted, human CD8 ${ }^{+}$cytotoxic T lymphocyte (CTL) clones. Recognition of NS3 amino acids 500 to 508 by CTL clones of two different serotype specificities. J. Immunol. 154, 1287-1295 (1995).

42. Mongkolsapaya, J. et al. Original antigenic sin and apoptosis in the pathogenesis of dengue hemorrhagic fever. Nat. Med. 9, 921-927 (2003).

This paper describes original antigenic sin in $\mathrm{T}$ cell responses to dengue virus infection.

43. Mongkolsapaya, J. et al. T cell responses in dengue hemorrhagic fever: are cross-reactive T cells suboptimal? J. Immunol. 176, 3821-3829 (2006).

44. Weiskopf, D. et al. Comprehensive analysis of dengue virus-specific responses supports an HLA-linked protective role for $\mathrm{CD}^{+}$T cells. Proc. Natl Acad. Sci. USA 110, E2046-E2053 (2013).

This study shows that cross-reactive $\mathrm{T}$ cells from primary infection expand during secondary infection (original antigenic sin), but the overal quality of the responses is not compromised.

45. Yauch, L. E. et al. A protective role for dengue virusspecific CD8+ T cells. J. Immunol. 182, 4865-4873 (2009).

This study shows the protective role of $\mathrm{CD} 8+{ }^{+} \mathrm{T}$ cells in a mouse model of dengue virus infection.

46. Mathew, A., Townsley, E. \& Ennis, F. A. Elucidating the role of $\mathrm{T}$ cells in protection against and pathogenesis of dengue virus infections. Future Microbiol. 9, 411-425 (2014)

47. Rivino, L. et al. Differential targeting of viral components by $\mathrm{CD}^{+}{ }^{+}$versus $\mathrm{CD} 8{ }^{+} \mathrm{T}$ lymphocytes in dengue virus infection. J. Virol. 87, 2693-2706 (2013). 
48. Zompi, S., Santich, B. H., Beatty, P. R. \& Harris, E. Protection from secondary dengue virus infection in a mouse model reveals the role of serotype cross reactive B and T cells. J. Immunol. 188, 404-416 (2012).

This study demonstrates that both cross-reactive antibodies and $\mathrm{T}$ cells protect mice from secondary heterotypic dengue virus infection.

49. Mathew, A. et al. Dominant recognition by human CD8 ${ }^{+}$cytotoxic $T$ lymphocytes of dengue virus nonstructural proteins NS3 and NS1.2a. J. Clin. Invest. 98, 1684-1691 (1996).

50. Mathew, A. et al. Predominance of HLA-restricted cytotoxic T-lymphocyte responses to serotype-crossreactive epitopes on nonstructural proteins following natural secondary dengue virus infection. J. Virol. 72 3999-4004 (1998).

51. Green, S. et al. Early CD69 expression on peripheral blood lymphocytes from children with dengue hemorrhagic fever. J. Infect. Dis. 180, 1429-1435 (1999).

52. Zivna, I. et al. $\mathrm{T}$ cell responses to an $\mathrm{HLA}-\mathrm{B}^{*} 07$ restricted epitope on the dengue NS3 protein correlate with disease severity. J. Immunol. 168 5959-5965 (2002).

53. Dung, N. T. et al. Timing of $\mathrm{CD} 8{ }^{+} \mathrm{T}$ cell responses in relation to commencement of capillary leakage in children with dengue. J. Immunol. 184, 7281-7287 (2010).

54. Friberg, H. et al. Cross-reactivity and expansion of dengue-specific T cells during acute primary and secondary infections in humans. Sci. Rep. 1, 51 (2011).

55. Rivino, L. et al. Virus-specific T lymphocytes home to the skin during natural dengue infection. Sci. Transl. Med. 7, 278 ra35 (2015). This study demonstrates that dengue virus-specific T cells migrate to peripheral tissues, such as the skin, during the acute phase of infection.

56. Kurane, I., Meager, A. \& Ennis, F. A. Dengue virusspecific human T cell clones. Serotype crossreactive proliferation, interferon $\gamma$ production, and cytotoxic activity. J. Exp. Med. 170, 763-775 (1989).

57. Kurane, I., Brinton, M. A., Samson, A. L. \& Ennis, F. A Dengue virus-specific, human CD4+ ${ }^{+} D 8^{-}$cytotoxic T-cell clones: multiple patterns of virus cross-reactivity recognized by NS3-specific T-cell clones. J. Virol. 65, 1823-1828 (1991).

58. Fazekas de St, G. \& Webster, R. G. Disquisitions of original antigenic sin. I. Evidence in man. J. Exp. Med. 124, 331-345 (1966).

59. Singh, R. A., Rodgers, J. R. \& Barry, M. A. The role of $T$ cell antagonism and original antigenic sin in genetic immunization. J. Immunol. 169, 6779-6786 (2002).

60. Weiskopf, D. et al. Dengue virus infection elicits highly polarized CX3CR $1+$ cytotoxic $\mathrm{CD} 4{ }^{+} \mathrm{T}$ cells associated with protective immunity. Proc. Natl Acad. Sci. USA 112, E4256-E4263 (2015)

61. Coffey, L. L. et al. Human genetic determinants of dengue virus susceptibility. Microbes Infect. 11, 143-156 (2009)

62. Yauch, L. E. et al. CD4 ${ }^{+} \mathrm{T}$ cells are not required for the induction of dengue virus-specific $\mathrm{CD}^{+} \mathrm{T}$ cell or antibody responses but contribute to protection after vaccination. J. Immunol. 185, 5405-5416 (2010).

63. Zellweger, R. M. et al. CD8 ${ }^{+} \mathrm{T}$ cells can mediate short-term protection against heterotypic dengue reinfection in mice. J. Virol. 89, 6494-6505 (2015).

64. Halstead, S. B. Controversies in dengue pathogenesis Paediatr. Int. Child Health 32, 5-9 (2012).

65. Guzman, M. G., Alvarez, M. \& Halstead, S. B. Secondary infection as a risk factor for dengue hemorrhagic fever/dengue shock syndrome: an historical perspective and role of antibody-dependent enhancement of infection. Arch. Virol. 158, 1445-1459 (2013).

66. Chan, K. R. et al. Leukocyte immunoglobulin-like receptor B1 is critical for antibody-dependent dengue. Proc. Natl Acad. Sci. USA 111, 2722-2727 (2014).

67. Zompi, S. \& Harris, E. Animal models of dengue virus infection. Viruses 4, 62-82 (2012).

68. Simmons, C. P. et al. Maternal antibody and viral factors in the pathogenesis of dengue virus in infants. J. Infect. Dis. 196, 416-424 (2007).

69. Halstead, S. B. et al. Dengue hemorrhagic fever in infants: research opportunities ignored. Emerg. Infect. Dis. 8, 1474-1479 (2002).
70. Kliks, S. C., Nimmanitya, S., Nisalak, A. \& Burke, D. S Evidence that maternal dengue antibodies are important in the development of dengue hemorrhagic fever in infants. Am. J. Trop. Med. Hyg. 38, 411-419 (1988).

References 68 and 70 demonstrate that maternal antibodies contribute to the development of severe disease in infants experiencing primary dengue virus infection.

71. Pierson, T. C. Modeling antibody-enhanced dengue virus infection and disease in mice: protection or pathogenesis? Cell Host Microbe 7, 85-86 (2010)

72. Mohsin, S. N. et al. Association of FcyRlla polymorphism with clinical outcome of dengue infection: first insight from Pakistan. Am. J. Trop. Med. Hyg. 93, 691-696 (2015)

73. Garcia, G. et al. Asymptomatic dengue infection in a Cuban population confirms the protective role of the RR variant of the FcyRlla polymorphism. Am. J. Trop. Med. Hyg. 82, 1153-1156 (2010)

74. Loke, H. et al. Susceptibility to dengue hemorrhagic fever in Vietnam: evidence of an association with variation in the vitamin $D$ receptor and Fcy receptor Ila genes. Am. J. Trop. Med. Hyg. 67, 102-106 (2002)

75. da Silva Voorham, J. M. et al. Antibodies against the envelope glycoprotein promote infectivity of immature dengue virus serotype 2. PLOS ONE 7, e29957 (2012)

76. Rodenhuis-Zybert, I. A. et al. A fusion-loop antibody enhances the infectious properties of immature flavivirus particles. J. Virol. 85, 11800-11808 (2011). This paper shows that immature dengue virions can be driven to become infectious through ADE.

77. Midgley, C. M. et al. An in-depth analysis of original antigenic sin in dengue virus infection. J. Virol. 85 410-421 (2011).

78. Pierson, T. C. et al. The stoichiometry of antibodymediated neutralization and enhancement of West Nile virus infection. Cell Host Microbe 1, 135-145 (2007)

This study measured the number of antibodies required for neutralization and enhancement of infection.

79. Guzman, M. G. et al. Neutralizing antibodies after infection with dengue 1 virus. Emerg. Infect. Dis. 13 282-286 (2007)

80. Sabin, A. B. Research on dengue during World War, II. Am. J. Trop. Med. Hyg. 1, 30-50 (1952)

81. Bhamarapravati, N. \& Sutee, Y. Live attenuated tetravalent dengue vaccine. Vaccine 18 (Suppl. 2), 44-47 (2000).

82. Sun, W. et al. Phase 2 clinical trial of three formulations of tetravalent live-attenuated dengue vaccine in flavivirus-naive adults. Hum. Vaccin. $\mathbf{5}$, 33-40 (2009).

83. Edelman, R. et al. Phase I trial of 16 formulations of a tetravalent live-attenuated dengue vaccine. Am. J. Trop. Med. Hyg. 69, 48-60 (2003).

84. Kanesa-thasan, N. et al. Safety and immunogenicity of attenuated dengue virus vaccines (Aventis Pasteur) in human volunteers. Vaccine 19, 3179-3188 (2001)

85. Guy, B. et al. From research to phase III: preclinical, industrial and clinical development of the Sanofi Pasteur tetravalent dengue vaccine. Vaccine 29 7229-7241 (2011)

86. Kirkpatrick, B. D. et al. Robust and balanced immune responses to all 4 dengue virus serotypes following administration of a single dose of a live attenuated tetravalent dengue vaccine to healthy, flavivirus-naive adults. J. Infect. Dis. 212, 702-710 (2015)

87. Osorio, J. E. et al. Safety and immunogenicity of a recombinant live attenuated tetravalent dengue vaccine (DENVax) in flavivirus-naive healthy adults in Colombia: a randomised, placebo-controlled, phase study. Lancet Infect. Dis. 14, 830-838 (2014).

88. Watanaveeradej, V. et al. Safety and immunogenicity of a rederived, live-attenuated dengue virus vaccine in healthy adults living in Thailand: a randomized trial. Am. J. Trop. Med. Hyg. 91, 119-128 (2014).

89. Villar, L. A. et al. Safety and immunogenicity of a recombinant tetravalent dengue vaccine in 9-16 year olds: a randomized, controlled, phase II trial in Latin America. Pediatr. Infect. Dis. J. 32, 1102-1109 (2013)

90. Sabchareon, A. et al. Protective efficacy of the recombinant, live-attenuated, CYD tetravalent dengue vaccine in Thai schoolchildren: a randomised, controlled phase 2b trial. Lancet 380, 1559-1567 (2012)
91. Lanata, C. F. et al. Immunogenicity and safety of tetravalent dengue vaccine in $2-11$ year-old previously vaccinated against yellow fever: randomized, controlled, phase II study in Piura, Peru. Vaccine 30, 5935-5941 (2012).

92. Leo, Y. S. et al. Immunogenicity and safety of recombinant tetravalent dengue vaccine (CYD-TDV) in individuals aged 2-45y: Phase II randomized controlled trial in Singapore. Hum. Vaccin. Immunother 8, 1259-1271 (2012).

93. Capeding, R. Z. et al. Live-attenuated, tetravalent dengue vaccine in children, adolescents and adults in a dengue endemic country: randomized controlled phase I trial in the Philippines. Vaccine $\mathbf{2 9}$ 3863-3872 (2011).

94. Villar, L. et al. Efficacy of a tetravalent dengue vaccine in children in Latin America. N. Engl. J. Med. 372 113-123 (2015)

95. Capeding, M. R. et al. Clinical efficacy and safety of a novel tetravalent dengue vaccine in healthy children in Asia: a phase 3, randomised, observer-masked, placebo-controlled trial. Lancet 384, 1358-1365 (2014).

References 94 and 95 describe the first ever Phase III trial of a dengue vaccine, which showed an overall efficacy of $64.7 \%$ in children from Latin America and $56.5 \%$ in Asian children, respectively.

96. Hadinegoro, S. R. et al. Efficacy and long-term safety of a dengue vaccine in regions of endemic disease. N. Engl. J. Med. 373, 1195-1206 (2015). This study is a 3-year follow up of the CYD-TDV vaccine involving 35,000 children; vaccine efficacy was higher in children over 9 years old compared with children younger than 9 years, and the younger age group was also associated with increased hospitalization.

97. Wu, S. F. et al. Evaluation of protective efficacy and immune mechanisms of using a non-structural protein NS1 in DNA vaccine against dengue 2 virus in mice. Vaccine 21, 3919-3929 (2003).

98. Amorim, J. H. et al. Protective immunity to DENV2 after immunization with a recombinant NS1 protein using a genetically detoxified heat-labile toxin as an adjuvant. Vaccine 30, 837-845 (2012).

99. Bhoomiboonchoo, P. et al. Sequential dengue virus infections detected in active and passive surveillance programs in Thailand, 1994-2010. BMC Publ. Health 15, 250 (2015).

100. Olkowski, S. et al. Reduced risk of disease during postsecondary dengue virus infections. J. Infect. Dis. 208, 1026-1033 (2013)

101. Gibbons, R. V. et al. Analysis of repeat hospital admissions for dengue to estimate the frequency of third or fourth dengue infections resulting in admissions and dengue hemorrhagic fever, and serotype sequences. Am. J. Trop. Med. Hyg. 77, 910-913 (2007).

102. Guy, B. et al. Evaluation of interferences between dengue vaccine serotypes in a monkey model. Am. J. Trop. Med. Hyg. 80, 302-311 (2009).

103. Dayan, G. H et al. Assessment of bivalent and tetravalent dengue vaccine formulations in flavivirusnaive adults in Mexico. Hum. Vaccin. Immunother. 10 2853-2863 (2014).

104. Durbin, A. P. et al. A single dose of any of four different live attenuated tetravalent dengue vaccines is safe and immunogenic in flavivirus-naive adults: a randomized, double-blind clinical trial. J. Infect. Dis. 207, 957-965 (2013).

105. George, S. L. et al. Safety and immunogenicity of a live attenuated tetravalent dengue vaccine candidate in flavivirus-naive adults: a randomized, double-blinded Phase 1 clinical trial. J. Infect. Dis. 212, 1032-1041 (2015).

106. Thomas, S. J. \& Rothman, A. L. Trials and tribulations on the path to developing a dengue vaccine. Vaccine http://dx.doi.org/10.1016/j.vaccine.2015.05.095 (2015).

This is a comprehensive review on dengue vaccine development.

107. Brien, J. D. et al. Genotype-specific neutralization and protection by antibodies against dengue virus type 3 J. Virol. 84, 10630-10643 (2010).

108. Crill, W. D. \& Roehrig, J. T. Monoclonal antibodies that bind to domain III of dengue virus E glycoprotein are the most efficient blockers of virus adsorption to Vero cells. J. Virol. 75, 7769-7773 (2001).

109. Gromowski, G. D. \& Barrett, A. D. Characterization of an antigenic site that contains a dominant, type-specific neutralization determinant on the envelope protein domain III (ED3) of dengue 2 virus. Virology 366, 349-360 (2007). 
110. Gromowski, G. D., Barrett, N. D. \& Barrett, A. D. Characterization of dengue virus complex-specific neutralizing epitopes on envelope protein domain III of dengue 2 virus. J. Virol. 82, 8828-8837 (2008).

111. Roehrig, J. T., Bolin, R. A. \& Kelly, R. G. Monoclonal antibody mapping of the envelope glycoprotein of the dengue 2 virus, Jamaica. Virology 246, 317-328 (1998).

112. Shrestha, B. et al. The development of therapeutic antibodies that neutralize homologous and heterologous genotypes of dengue virus type 1 PLoS Pathog. 6, e1000823 (2010).

113. Sukupolvi-Petty, S. et al. Structure and function analysis of therapeutic monoclonal antibodies against dengue virus type 2. J. Virol. 84, 9227-9239 (2010) This is one of several studies from this group defining the epitopes that are recognized by protective antibodies and showing that the viral strains and/or genotypes have an influence on neutralizing potency.

114. Sukupolvi-Petty, S. et al. Type- and subcomplex specific neutralizing antibodies against domain III of dengue virus type 2 envelope protein recognize adjacent epitopes. J. Virol. 81, 12816-12826 (2007).

115. Sukupolvi-Petty, S. et al. Functional analysis of antibodies against dengue virus type 4 reveals strain-dependent epitope exposure that impacts neutralization and protection. J. Virol. 87 8826-8842 (2013)

116. Wahala, W. M. et al. Natural strain variation and antibody neutralization of dengue serotype 3 viruses. PLoS Pathog. 6, e1000821 (2010)

117. Oliphant, T. et al. Antibody recognition and neutralization determinants on domains I and II of West Nile Virus envelope protein. J. Virol. $\mathbf{8 0}$, 12149-12159 (2006)

118. Lai, C.-Y. et al. Antibodies to envelope glycoprotein of dengue virus during the natural course of infection are predominantly cross-reactive and recognize epitopes containing highly conserved residues at the fusion loop of domain II. J. Virol. 82, 6631-6643 (2008).

119. Oliphant, T. et al. Induction of epitope-specific neutralizing antibodies against West Nile virus. J. Virol. 81, 11828-11839 (2007)

120. Crill, W. D., Hughes, H. R., Delorey, M. J. \& Chang, G. J. Humoral immune responses of dengue fever patients using epitope-specific serotype- 2 virus like particle antigens. PLOS ONE 4, e4991 (2009).

121. Smith, S. A. et al. The potent and broadly neutralizing human dengue virus-specific monoclonal antibody $1 \mathrm{C} 19$ reveals a unique cross-reactive epitope on the bc loop of domain II of the envelope protein. MBio 4, e00873-00813 (2013).

This paper shows the characterization of a panel of human mAbs and the identification of an antibody that recognizes all four dengue virus serotypes with potent neutralizing activity. The epitope of this mAb was shown to be on the BC loop of a monomeric E protein.

122. Robinson, L. N. et al. Structure-guided design of an anti-dengue antibody directed to a nonimmunodominant epitope. Cell 162, 493-504 (2015).

123. Oliphant, T. et al. Development of a humanized monoclonal antibody with therapeutic potential against West Nile virus. Nat. Med. 11, 522-530 (2005).
124. Lok, S. M. et al. Binding of a neutralizing antibody to dengue virus alters the arrangement of surface glycoproteins. Nat. Struct. Mol. Biol. 15, 312-317 (2008).

This interesting paper describes the crystal structure of the mAb 1A1D2 binding to the viral $\mathrm{E}$ protein, which reorganizes to expose hidden epitopes, suggesting that the virus can 'breathe' to accommodate antibody binding.

125. Williams, K. L., Wahala, W. M., Orozco, S de Silva, A. M. \& Harris, E. Antibodies targeting dengue virus envelope domain III are not required for serotype-specific protection or prevention of enhancement in vivo. Virology 429, 12-20 (2012).

126. Midgley, C. M. et al. Structural analysis of a dengue cross-reactive antibody complexed with envelope domain III reveals the molecular basis of crossreactivity. J. Immunol. 188, 4971-4979 (2012)

127. Dowd, K. A., Jost, C. A., Durbin, A. P., Whitehead, S. S. \& Pierson, T. C. A dynamic landscape for antibody binding modulates antibody-mediated neutralization of West Nile virus. PLoS Pathog 7, e1002111 (2011)

128. Fibriansah, G. et al. Structural changes in dengue virus when exposed to a temperature of $37{ }^{\circ} \mathrm{C}$. J. Virol. 87, 7585-7592 (2013).

129. Zhang, X. et al. Dengue structure differs at the temperatures of its human and mosquito hosts. Proc. Natl Acad. Sci. USA 110, 6795-6799 (2013).

130. Fibriansah, G. et al. Dengue virus. Cryo-EM structure of an antibody that neutralizes dengue virus type 2 by locking E protein dimers. Science $349,88-91$ (2015)

131. Traggiai, E. et al. An efficient method to make human monoclonal antibodies from memory B cells: potent neutralization of SARS coronavirus. Nat. Med. 10 871-875 (2004)

132. Yu, X., McGraw, P. A., House, F. S. \& Crowe, J. E. Jr. An optimized electrofusion-based protocol for generating virus-specific human monoclonal antibodies. J. Immunol. Methods 336, 142-151 (2008).

133. Smith, K. et al. Rapid generation of fully human monoclonal antibodies specific to a vaccinating antigen. Nat. Protoc. 4, 372-384 (2009).

134. Beltramello, M. et al. The human immune response to Dengue virus is dominated by highly crossreactive antibodies endowed with neutralizing and enhancing activity. Cell Host Microbe 8, 271-283 (2010)

135. de Alwis, R. et al. In-depth analysis of the antibody response of individuals exposed to primary dengue virus infection. PLoS Negl Trop. Dis. 5, e1188 (2011).

136. Smith, S. A. et al. Persistence of circulating memory $B$ cell clones with potential for dengue virus disease enhancement for decades following infection. J. Virol. 86, 2665-2675 (2012).

137. Smith, S. A. et al. Human monoclonal antibodies derived from memory B cells following live attenuated dengue virus vaccination or natural infection exhibit similar characteristics. J. Infect. Dis. 207, 1898-1908 (2013).

138. Oceguera, L. F. et al. Flavivirus serology by western blot analysis. Am. J. Trop. Med. Hyg. 77, 159-163 (2007)

139. Teoh, E. P. et al. The structural basis for serotypespecific neutralization of dengue virus by a human antibody. Sci. Transl. Med. 4, 139ra83 (2012).
140. Fibriansah, G et al. A potent anti-dengue human antibody preferentially recognizes the conformation of E protein monomers assembled on the virus surface. EMBO Mol. Med. 6, 358-371 (2014).

141. Rouvinski, A. et al. Recognition determinants of broadly neutralizing human antibodies against dengue viruses. Nature 520, 109-113 (2015).

142. Kaufmann, B. et al. Neutralization of West Nile virus by cross-linking of its surface proteins with Fab fragments of the human monoclonal antibody CR4354. Proc. Natl Acad. Sci. 107, 18950-18955 (2010)

143. Fibriansah, G. et al. A highly potent human antibody neutralizes dengue virus serotype 3 by binding across three surface proteins. Nat. Commun. 6, 6341 (2015). References 130,139, 140 and 143 are EM studies that show the binding of potent dengue virus serotype-specific antibodies recognizing conformation-dependent epitopes. All but one recognize epitopes across three E protein monomers of the two adjacent dimers on the viral particle.

144. McLellan, J S et al Structure of RSV fusion glycoprotein trimer bound to a prefusion-specific neutralizing antibody. Science 340, 1113-1117 (2013).

145. McLellan, J. S. et al. Structure-based design of a fusion glycoprotein vaccine for respiratory syncytial virus. Science 342, 592-598 (2013)

146. Yacoub, S., Wertheim, H., Simmons, C. P., Screaton, G $\&$ Wills, B. Cardiovascular manifestations of the emerging dengue pandemic. Nat. Rev. Cardiol. 11 335-345 (2014).

147. Trung, D. T. et al. Clinical features of dengue in a large Vietnamese cohort: intrinsically lower platelet counts and greater risk for bleeding in adults than children PLoS Negl Trop. Dis. 6, e1679 (2012).

148. Whitehorn, J. et al. Dengue therapeutics, chemoprophylaxis, and allied tools: state of the art and future directions. PLoS Negl Trop. Dis. 8, e3025 (2014).

149. Mackenzie, J. S., Gubler, D. J. \& Petersen, L. R. Emerging flaviviruses: the spread and resurgence of Japanese encephalitis, West Nile and dengue viruses. Nat. Med. 10, S98-S109 (2004).

150. Williams, K. L. et al. Therapeutic efficacy of antibodies lacking Fcy receptor binding against lethal dengue virus infection is due to neutralizing potency and blocking of enhancing antibodies [corrected] PLoS Pathog. 9, e1003157 (2013)

151. Smith, S. A. et al. Isolation of dengue virus-specific memory B cells with live virus antigen from human subjects following natural infection reveals the presence of diverse novel functional groups of antibody clones. J. Virol. 88, 12233-12241 (2014).

152. de Alwis, R. et al. Identification of human neutralizing antibodies that bind to complex epitopes on dengue virions. Proc Natl Acad. Sci. USA 109, 7439-7444 (2012).

\section{Acknowledgements}

This work was supported by the Wellcome Trust, the National Institute for Health Research (NIHR) Biomedical Research Centre funding scheme, and the European Commission Seventh Framework Programme [FP7/2007-2013] for the DENFREE project under the grant agreement $n^{\circ} 282$ 378. G.S. is a Wellcome Trust senior investigator.

Competing interests statement

The authors declare no competing interests. 